\title{
A comprehensive assessment of alternative absorber-exchanger designs for hybrid PVT-water collectors
}

\author{
María Herrando ${ }^{1,2,}$, Alba Ramos ${ }^{1,3}$, Ignacio Zabalza ${ }^{2}$, Christos N. Markides ${ }^{1}$ \\ ${ }^{1}$ Clean Energy Processes (CEP) Laboratory, Department of Chemical Engineering, Imperial College London, London, UK \\ ${ }^{2}$ School of Engineering and Architecture, University of Zaragoza, Zaragoza, Spain \\ 3 Solar Energy Institute, Technical University of Madrid, Spain \\ *Corresponding author: mherrando@unizar.es
}

N.B.: This is the ACCEPTED MANUSCRIPT version of this article. The final, published version of the article can be found at: https://doi.org/10.1016/i.apenergy.2018.11.024

\begin{abstract}
In this paper, 26 alternative absorber-exchanger designs for hybrid PV-thermal (PVT) solar collectors are proposed and compared against a reference-case, commercial sheet-and-tube PVT collector. The collectors involve different geometric design features based on the conventional sheet-and-tube configuration, and also on a newer flat-box structure constructed from alternative polymeric materials with the aim of maintaining or even improving heat transfer and overall (thermal and electrical) performance while achieving reductions to the overall weight and cost of the collectors. The main contributions of this research include: $i$ ) the development and validation of a detailed 3-D computational finite-element model of the proposed PVT collector designs involving multi-physics processes (heat transfer, fluid dynamics and solid mechanics); ii) results from comparative techno-economic analyses of the proposed PVT designs; and, iii) further insights from thermal stress and structural deformation analyses of the proposed collectors, which are crucial for ensuring long lifetimes and especially important in the case of polymeric collectors. The results show that, in general, the flatbox designs (characterised by a thin absorber plate) are not sensitive to the flow-channel size or construction material, at least within the range of investigation. A PVT collector featuring a polycarbonate (PC) flat-box design with $3 \times 2 \mathrm{~mm}$ rectangular channels appears to be a particularly promising alternative to commercial PVT collectors, achieving a slightly improved thermal performance compared to the reference case (with a $4 \%$ higher optical efficiency and 15\% lower linear heat-loss coefficient), while also lowering the weight (by around 9\%) and investment cost (by about 21\%) of the collector. The structural analysis shows that the maximum von Mises stress experienced in the absorber-exchanger of the PC flat-box collector is considerably lower than that in the copper sheet-and-tube collector ( $<13 \%$ vs. $64 \%$ of the material's yield stress), which is attributed to the larger thermal expansion of the PC absorber-exchanger, that leads to lower stresses. Therefore, the proposed PC flat-box design is not expected to suffer higher strains than the commercially-available PVT collector.
\end{abstract}

\section{Keywords:}

absorber-exchanger, cost savings, efficiency, hybrid PVT collector, solar energy, structural analysis 


\section{Nomenclature}

\section{Abbreviations}

$\begin{array}{ll}\text { AAD } & \text { Average Absolute Deviation } \\ \text { BC } & \text { Boundary Conditions } \\ \text { CFD } & \text { Computational Fluid Dynamics } \\ \text { DHW } & \text { Domestic Hot Water } \\ \text { EVA } & \text { Ethylene-Vinyl Acetate } \\ \text { FEM } & \text { Finite Element Method } \\ \text { hBN } & \text { Hexagonal Boron Nitride } \\ \text { IEA } & \text { International Energy Agency } \\ \text { NBL } & \text { Number of Boundary Layers } \\ \text { PA } & \text { Polyamide } \\ \text { PC } & \text { Polycarbonate } \\ \text { PA90 } & \text { Polyamide (grade) Zytel }{ }^{\circledR} \text { RS LC3090 NC010 } \\ \text { PA30 } & \text { Polyamide (grade) Zytel }{ }^{\circledR} \text { RS LC3030 NC010 } \\ \text { PBT } & \text { Payback Time } \\ \text { PV } & \text { Photovoltaic } \\ \text { PVT } & \text { (Hybrid solar) PV and Thermal collector } \\ \text { PVT-w } & \text { (Hybrid solar) PVT-water collector } \\ \text { R\&D } & \text { Research \& Development } \\ \text { ST } & \text { Solar Thermal } \\ \text { UTS } & \text { Ultimate Tensile Stress }\end{array}$

\section{Symbols}

$a_{1} \quad$ Linear heat-loss coefficient (-)

$a_{2} \quad$ Quadratic heat-loss coefficient (-)

$A_{\mathrm{c}} \quad$ PVT collector aperture area $\left(\mathrm{m}^{2}\right)$

$A_{\mathrm{p}} \quad$ Riser pipe/channel transversal area $\left(\mathrm{m}^{2}\right)$

$A_{\mathrm{pT}} \quad$ Total riser pipe/channel transversal area $\left(A_{\mathrm{p}} \cdot n\right)\left(\mathrm{m}^{2}\right)$

$B \quad$ Total PVT collector width (m)

$c_{p} \quad$ Specific heat capacity $(\mathrm{J} / \mathrm{kg} \mathrm{K})$

$C_{0} \quad$ Investment costs (€)

$D$

$F_{\mathrm{R}}$

$\boldsymbol{F}_{\mathrm{V}}$

G

$g$

Gr

h

$H_{\mathrm{b}}$

I

k

L

$\dot{m}_{\text {tube }}$

n

$q$

$R e$

$S$

$T$

$t$

U

$U_{\mathrm{L}}$

$v_{\mathrm{w}}$

$V_{\text {wind }}$

$w_{\mathrm{e}}$
W

$W_{\mathrm{b}} \quad$ Flat-box channel width (m)

\section{Greek}

$\alpha_{\mathrm{PV}} \quad$ Solar absorption coefficient of the PV module (-)

$\beta_{0} \quad$ Temperature coefficient for the PV module $(1 / \mathrm{K})$

$\varepsilon_{\mathrm{g}} \quad$ Emissivity of the glass cover (-)

$\varepsilon_{\mathrm{PV}} \quad$ Emissivity of the PV module (-)

$\varepsilon \quad$ Strain tensor (-)

$\delta \quad$ Thickness (m)

$\lambda \quad$ Lame constant $\left(\mathrm{N} / \mathrm{m}^{2}\right)$

$\eta \quad$ Efficiency (\%)

$\mu_{\mathrm{w}} \quad$ Dynamic viscosity of water $(\mathrm{kg} / \mathrm{m} \mathrm{s})$

$\rho_{\mathrm{d}} \quad$ Diffuse reflectance of the cover plate $(-)$

$\rho \quad$ Density $\left(\mathrm{kg} / \mathrm{m}^{3}\right)$

$\sigma_{\mathrm{c}} \quad$ Cauchy stress tensor $\left(\mathrm{N} / \mathrm{m}^{2}\right)$

$\sigma_{\mathrm{M}} \quad$ Von Mises stress (MPa)

$\sigma_{\mathrm{x} / \mathrm{y} / \mathrm{z}} \quad$ Stress tensor (MPa)

$\sigma \quad$ Stefan-Boltzmann constant $\left(=5.67 \cdot 10^{-8} \mathrm{~W} / \mathrm{m}^{2} \mathrm{~K}^{4}\right)$

$\theta \quad$ PVT collector tilt angle $\left({ }^{\circ}\right)$

$\tau_{\mathrm{g}} \quad$ Transmittance of the glass cover (-)

$(\tau \alpha)_{\mathrm{PV}}$ Transmittance-absorptance product for the PV module (-)

\section{Subscripts}

\begin{tabular}{ll} 
a & Ambient \\
abs & Absorber \\
arg & Argon (ideal gas) \\
back & Back of the PVT collector \\
cv & Convection \\
dis & Dissipation \\
e & Electrical \\
F & Forces \\
fm & Mean fluid \\
g1 & Outer glass cover \\
g2 & PV glass cover \\
ins & Insulation layer \\
in & Mains water entering the water storage tank \\
long $\lambda$ & Long wavelengths $(2.5-40 \mu \mathrm{m})$ \\
o & Optical \\
PV & PV cells \\
$\mathrm{r}$ & Reduced \\
ref & Reference PV cell values at an ambient temperature of \\
& Ta = 25 ${ }^{\circ}$ C and a solar irradiance of G $=1000 \mathrm{~W} / \mathrm{m}^{2}(\mathrm{~K})$ \\
rd & Radiation \\
sky & Sky \\
short $\lambda$ & Short wavelengths $(0.4-2.5 \mu \mathrm{m})$ \\
$\mathrm{t}$ & Total solar radiation \\
th & Thermal \\
top & Top of the PVT collector \\
$\mathrm{u}$ & Useful heat from the absorber to the water \\
$\mathrm{w}$ & Water \\
wind & Wind \\
& \\
\hline
\end{tabular}




\section{Introduction}

Solar energy can be converted to electricity by means of either Photovoltaic (PV) or Solar Thermal (ST) technologies [1,2], the latter of which can generate electrical power either in large-scale Concentrated Solar Power (CSP) plants or in distributed small/medium-scale systems based on non-concentrating or lowconcentration ST collectors [3-6]. Although it is widely acknowledged that the electricity-only generating costs (e.g., levelised cost of electricity, or LCOE) of PV systems are lower than those of CSP equivalents, CSP/ST systems have traditionally had advantages in terms of their ability to co-generate useful heat in socalled Solar Combined Heat and Power (S-CHP) configurations, as well as to provide options for flexibility with thermal energy storage (TES) that comes at a significantly lower cost than equivalent electrical energy storage. More recently, hybrid Photovoltaic-Thermal (PVT) systems have been proposed that synergistically combine the characteristics and advantages of PV and ST systems, and are thus capable of satisfying both the electrical and thermal needs of buildings and end-users in urban environments. PVT systems are a more attractive and efficient solution when available space is limited [7-9], i.e., in urban areas, as these systems are able to generate both electricity and a thermal output simultaneously from the same area [10,11]; and appear as highly suitable solutions for combined energy (heat and power) provision [12,13].

Amongst the various potential liquid substances for PVT applications, water is by far the most commonly employed fluid $[14,15]$. Hence, it is no surprise that significant research has been dedicated in recent years to a number of PVT water (PVT-w) systems covering material selection, design and operation $[7,16,17]$. PVT-w systems have been shown to be capable of higher electrical efficiencies compared to PV modules, by up to $\sim 15 \%$, while also generating Domestic Hot Water (DHW) and/or providing space heating [18]. Consequently, PVT-w technology is considered to have an especially important potential in the residential sector [19-21], where there are both thermal-energy and electricity demands [22,23]. Previous research undertaken by the authors concluded that PVT-w systems can cover up to about $50 \%$ of the total electricity demand, and 35-50\% of the DHW demand of a typical household in London (UK) [12,22], while fully covering the electrical demand and $\sim 70 \%$ of the DHW demand of a household in Larnaca (Cyprus) [24].

In these PVT ${ }^{1}$ collectors, copper is the most widespread solid material used [12], and the sheet-and-tube arrangement is the most common absorber-exchanger design found in literature and employed in commercially available PVT collectors [21,25-28]. Beyond the absorber-exchanger configuration, several collector designs have been considered $[7,13,26]$, including uncovered (unglazed), with one or two glass covers (glazed), with or without a gap between the cover(s) and PV cells, filled with air, other inert gases or even a vacuum (evacuated). Previous work [13,29] concluded that the use of inert gases is promising, as this significantly reduces the convective heat-loss from the top surface. Consequently, it was decided to use in this work the commercial sheet-and-tube PVT collector (ECOMESH panel from the company EndeF Engineering [30]) as a benchmark reference case, as it has an innovative cover filled with inert gas, which improves significantly the collector's thermal performance while maintaining a high electrical output.

In an attempt to improve the bonding quality and heat transfer of PVT collectors, some alternative absorberexchanger designs such as the flat-box structure made of aluminium alloy have been proposed [25,31,32]. The present research considers an aluminium alloy flat-box design as a first alternative to the reference case. In addition, this research proposes alternative flat-box designs made of polymer, as it is believed that some polymeric materials have properties that make them an interesting option for PVT collectors [16,33], including their low density, good mechanical strength, lack of need for special surface treatments, corrosion resistance, ease of mass production manufacturing with the additional benefit of having fewer components to assemble, and lower production cost thanks to the low-cost material and reduced manufacturing time. Nevertheless, some properties of polymers, such as their lower thermal conductivity, large thermal expansion, lower mechanical strength and limited service temperature, are disadvantageous for this type of application [16]. For these reasons, structural and thermal expansion analyses are particularly important. The ideal polymer should have high Ultraviolet, water and glycol resistance/compatibility, good chemically

\footnotetext{
${ }^{1}$ For simplicity, from this point onwards, all references to PVT specifically refer to PVT-water collectors.
} 
stability, high thermal conductivity, good thermal range of utilisation $\left(-10 /+150^{\circ} \mathrm{C}\right)$ and good mechanical strength [33-35]. With this in mind, two polymers are proposed: i) polycarbonate (PC), as suggested by previous authors [34-36], and ii) polyamide (PA), without and with additives to improve its thermal conductivity [37], which have not been previously considered to the best knowledge of the authors.

Despite its potential, there are still very few PVT manufacturers and installers [38], and most products available on the market are not based on designs optimised specifically for PVT applications. Reviews of R\&D progress of PVT technology have highlighted the need to optimise the geometrical design of PVT collectors in order to enhance their performance [17], as well as to propose new thermal-absorber configurations $[7,19]$. At the same time, there is a strong drive for significant cost reductions to all ST technologies [39]. The International Energy Agency (IEA) has set a new task on PVT collectors (Task 60) under the Solar Heating and Cooling (SHC) programme which aims, among others, to improve the testing, modelling and adequate technical characterization of PVT collectors to boost the correct inclusion of PVT technology in simulation software, and to explore potential cost reductions in the balance of systems [40].

The main aim of the research reported in this paper is to propose improved PVT collectors with an optimal balance of energy efficiency, weight/strength, cost and ease of manufacture, specifically by considering alternative polymeric absorber-exchangers with geometrical designs that significantly reduce weight and cost relative to conventional (copper sheet-to-tube) designs, while maximising heat transfer and thereby improving or at least maintaining the overall (thermal and electrical) efficiency of the collectors.

Hybrid PVT collectors operate over a range of temperatures throughout a day, also depending on the solar irradiance and ambient temperature, and therefore on the location, with temperature differences between day and night of more than $60^{\circ} \mathrm{C}$. This temperature variation leads to thermal expansion stresses, which should be evaluated to ensure that the deformations in the collector structure, and specifically in each PVT material layer, are within permissible limits thereby avoiding structural failure. Typically, the most critical layers in a hybrid PVT collector are the encapsulation material and the PV cells [41,42]. The most common encapsulation material used in a wide variety of PV modules is elastomeric polymer. However, there is a significant difference between the thermal expansion coefficients of polymers and silicon cells, which leads to stresses throughout a diurnal cycle and can cause fractured cells, cracks and separation of the encapsulant, or broken interconnections [43]. Therefore, the encapsulant material should be able to accommodate the thermal expansion of the different materials without overstressing the PV cells and interconnections and must be resistant to fracture. The most common encapsulant material used is Ethylene Vinyl Acetate (EVA) [43], however, this encapsulant loses its mechanical properties at $130-140{ }^{\circ} \mathrm{C}$ and as a consequence can delaminate [43-45].

Meanwhile, PV laminates used in PVT collectors have usually the same specifications as those used in commercial PV modules, which are certified to operate safely up to $85^{\circ} \mathrm{C}$ according to the IEC 61215 standard [44,45], so in PVT applications the PV cells can suffer damage under rapid thermal expansion due to stress variations. In previous studies into the failure modes of PV modules [43], delamination at interfaces, water penetration, short circuits, cell interconnection failures and cracking of the solar cells from expansion/contraction stresses were identified, among others, as early failure modes.

Despite their importance, few studies in the literature to date are concerned with the effects of thermal stresses in PVT collectors, and those that address this topic focus mainly on overheating and stagnation phenomena $[44,46,47]$, rather than on the assessment of structural deformations and their effects on the different layers of a PVT collector. Most studies that address fatigue characterisation or performance requirements and loads focus on ST systems $[48,49]$, and those that consider the most critical layers (EVA encapsulant and PV cells) focus on PV modules [43]. Although the effects of high temperatures and thermal expansion are somewhat similar to ST and PV collectors, the conclusions of these studies should not be extrapolated to PVT collectors as the cooling effect of the liquid leads to different temperature gradients throughout the collector length in the various layers, and particularly the PV cells. Undertaking experimental studies to analyse thermal expansion and associated loads is expensive and complex, so a detailed theoretical model that incorporates the different materials and layers is important in identifying the critical components on which further, specific experimental considerations might be required. 
A number of 3-D CFD analyses have been undertaken in this context, mostly on flat-plate ST collectors [50-54] or solar air heaters [55]. A polymeric ST collector was modelled by CFD in Ref. [50] providing insight on the velocity field and pressure drop inside the collector channels. Nevertheless, very few papers have been found that study the performance of PVT collectors through 3-D CFD analyses. In particular, Refs. [56,57] consider copper sheet-and-tube PVT collectors, and the analysis focuses on the temperature and water flow distribution, so it would be of interest to extend these by addressing the thermal expansion and associated strains that PVT collectors suffer.

PV cells operating at a higher temperature or lower irradiance are known to generate a reduced electrical output [14]. Therefore, a detailed spatially-distributed PVT collector model is required to predict accurately the non-uniform temperature distribution over the solar cells and, ultimately, the performance of the whole collector. A temperature variation amounting to $\sim 10{ }^{\circ} \mathrm{C}$ over the surface of a sheet-and-tube PVT collector at normal operating conditions has been previously estimated, leading to a 5\% drop in the efficiency of cells at the identified hot regions compared to the cooler areas of the collector [24]. Thus, one objective of this work is to use the 3-D CFD-FEM model to identify any hot regions and to use this knowledge to design a module that attains uniform cooling by eliminating these as far as possible.

Thus, the main contributions of the present research include: i) the consideration of an innovative highefficiency PVT collector featuring a cover filled with inert gas (ECOMESH panel [30]), ii) the development and validation of a detailed 3-D CFD-FEM model of the PVT collector involving multi-physics processes (heat transfer, fluid dynamics and solid mechanics), iii) the thermal and electrical performance assessment of 26 alternative absorber-exchanger designs (plus a commercial PVT collector used as reference), including several flat-box and sheet-and-tube designs, and constructed with different materials (copper, aluminium, PC, PA with and without additives), all implemented within the same reference 3-D PVT collector model for benchmarking and comparison purposes, iv) the economic analysis and comparison of the proposed PVT collector designs and, v) thermal stress and structural deformation preliminary analyses of the proposed PVT collector designs, which are crucial for ensuring long lifetimes and especially important in the case of polymeric collectors.

In what follows, the specifications of the modelled PVT collector, employed methodology, assumptions, initial conditions and other such considerations are given in Section 2. Section 3 contains the main results and an associated discussion including model validation, parametric analyses, performance curve assessment, structural characterisation and technoeconomic analysis. Finally, Section 4 summarises the main conclusions from this investigation. Further details of the 3-D CFD-FEM model can be found in Appendix A, and a full list of the proposed PVT collector designs along with their features is detailed in Appendix B.

\section{Methodology}

The 3-D CFD-FEM model has been developed in the COMSOL platform, as its 3-D graphic capabilities facilitate the modelling of complex geometries that would not have been easy to model otherwise. Furthermore, COMSOL allows us to assess the thermal expansion of the absorber-exchanger due to temperature variations in the different material layers, which is of particular importance when polymeric materials are considered.

Firstly, the reference PVT collector (ECOMESH panel from company EndeF Engineering [30]) is modelled and the results are validated against experimentally-derived performance curves provided by the collector manufacturer. Once the 3-D CFD-FEM model of this commercial PVT collector has been developed and validated, the model can then be used with more confidence to evaluate the thermal performance of a range of alternative absorber-exchanger geometries employed the same collector. The other designs are then modelled by using the same model with modifications implemented to describe each specific alternative absorber-exchanger geometry and construction material. From the fluid temperature rise and heat flux obtained from the simulations over a range of steady-state operating conditions, it is possible to evaluate the optical efficiency $\left(\eta_{\mathrm{o}}\right)$, and linear and quadratic heat-loss coefficients $\left(a_{1}\right.$ and $a_{2}$ ). These are the characteristic parameters used to compare the thermal performance of PVT collectors according to the European standards for solar collector testing [58]. It is noted that in our simulations the PV electrical power output is also modelled in the PVT collectors and reported (see Figure 15), but the main focus of the present work is on the collectors' thermal performance so details on the 
electrical efficiency are only provided in the last analysis (see Section 3.5). Finally, a simple cost analysis is undertaken to assess the various configurations also from an economic perspective, for the case of Spain, which could be generalised to any country or region with similar natural gas and electricity prices.

\subsection{PVT collector modelling}

The PV cells and the thermal absorber are the two main components of a PVT collector. In Figure 1, the components of the collector are shown in detail: glazing, PV cells, EVA and Tedlar layers, absorber-exchanger (which corresponds to the thermal absorber and the riser water tubes/channels) and the insulation.
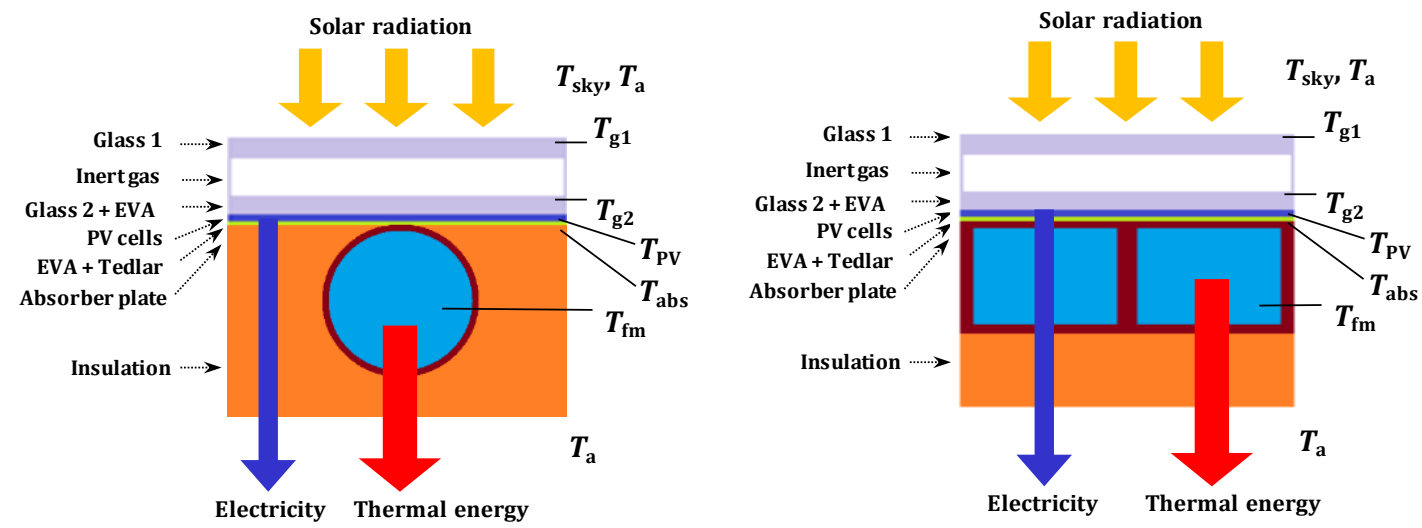

Figure 1. PVT collector cross-section showing the various collector layers for the (left) sheet-and-tube design, and (right) flat-box design (not to scale).

The detailed 3-D CFD-FEM model of the PVT collector involves three main physics: heat transfer, fluid dynamics and solid mechanics. Heat transfer equations apply to all domains conforming the PVT collector (i.e., cover and inner glasses, inert gas gap, PV layer, EVA and Tedlar layers, absorber plate and riser pipes, circulating fluid and insulation) $[12,26,59]$. The main heat transfer mechanisms are radiation (from the glass and the PV module to the sky, and the surface to surface radiation between Glass 1 and Glass 2), convection (from the outer surfaces to the ambient, within Glass 1 and Glass 2, and from the tubes/channels to the heat transfer fluid) and conduction (between all solid layers). Fluid dynamic equations apply to both liquid (circulating water) and gas (inert gas in the gap) domains, and solid mechanic equations are evaluated for all solid domains. Along with the three physics (heat transfer, fluid dynamics and solid mechanics), there are two main multiphysics involved, non-isothermal flow and thermal expansion. First of all, heat transfer and fluid dynamics physics are simultaneously solved, for which non-isothermal flow equations are considered in the fluid domains and thermal expansion is evaluated on the solid domains. Results obtained from this multi-physics calculation (e.g., temperature distribution, fluid velocity profiles, heat transfer between the different layers and domains) are fed in a second simulation step to solve the solid mechanics equations. The reason for dividing the problem into two steps is the high computational resources required to simultaneously solve three physics and related multi-physics. To make sure that the same results are obtained, we solved the problem with the three physics simultaneously for a S\&T design and a flat-box design, and we obtained virtually the same results (within numerical error). Governing equations and boundary conditions applied in this problem are detailed in Appendix A.

The PVT model is developed under the following assumptions:

- the absorption in the glass layers ('Glass 1' and 'Glass 2' in Figure 1) and in the frame are neglected [60];

- the ambient temperature is considered uniform around the collector [33,59] and heat losses from the sides of the PVT collector are negligible [59];

- solar irradiance and wind speed are uniform over the collector's surface area;

- the total water mass flow-rate is distributed uniformly amongst all collector channels with uniform inlet temperature [33,61];

- radiative thermal exchanges between the sides of the collector channels are neglected $[27,33,62,63]$;

The model is run under steady-state conditions $[26,64]$. 
In the case of detailed 3-D CFD-FEM simulations where there are multiple radiating surfaces and heat transfer mechanisms, and where fluid-dynamic equations should be solved simultaneously, as in the case of a PVT collector, the significant amount of time and computational resources required for the simulations becomes a challenge. Moreover, the particular collector geometries considered here have high aspect ratios, with pipe lengths $(L)$ being of the order of $1.5 \mathrm{~m}$, while the thicknesses of the various transverse layers are of the order of $10^{-4} \mathrm{~m}$, which complicate the meshing. For this reason, a swept mesh is used instead of a tetrahedral mesh as it fits better the geometries of interest and generates a structured mesh with higher element quality. To verify that the mesh selected does not lead to numerical inaccuracies, a convergence study over a range of mesh element sizes is also performed (see Section 3.1.1).

Furthermore, in order to reduce the computational cost without simplifying the physics (which would reduce the model accuracy) simplifications are made where possible, in particular by considering the inherent symmetry of the considered problems, i.e., designs, boundary conditions. For example, in the case of the sheet-and-tube design under the aforementioned assumptions, the heat transfer problem is solved for only one-half of a riser tube and the temperature profile is considered to be symmetric. Therefore, symmetry boundary conditions have been applied along the centreline of the sheet-and-tube PVT collector, thus only half-pipe and half-fin collector sections have been implemented in the 3-D CFD-FEM models [65].

The geometry of the flat-box structure is simpler to model, given its rectangular nature. In this work, we consider a single whole channel for higher aspect-ratio designs $(20 \times 10 \mathrm{~mm}$ and $40 \times 10 \mathrm{~mm})$ and two whole channels for lower aspect-ratio designs $(10 \times 10 \mathrm{~mm}, 6 \times 4 \mathrm{~mm}$ and $3 \times 2 \mathrm{~mm})$, as shown in Figure 2 .
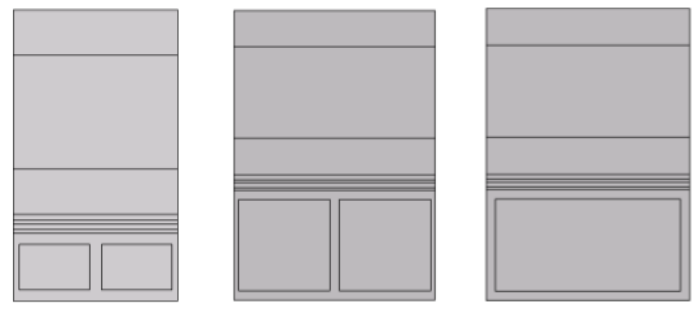

Figure 2. Cross section of: (left) two $6 \times 4 \mathrm{~mm}$ channels, (middle) two $10 \times 10 \mathrm{~mm}$ channels, and (right) one $20 \times 10 \mathrm{~mm}$ channel for the flat-box structure configuration as modelled in COMSOL.

Since there is currently no standard method to assess the performance of PVT collectors [9], both the ASHRAE [66] and ISO [67] characterisation approaches for ST collectors are followed in order to report and to compare the thermal efficiencies of the different PVT collector and absorber-exchanger designs. The ASHRAE method is based on the heat removal factor $\left(F_{\mathrm{R}}\right)$ and the overall heat-loss coefficient $\left(U_{\mathrm{L}}\right)$ of the collector [9], which can be obtained by calculating the thermal efficiency of the collector at different inlet temperatures at steady-state conditions [68-70],

$$
\eta_{\mathrm{th}}=\frac{q_{\mathrm{u}}}{I_{\mathrm{t}}}=F_{\mathrm{R}}(\tau \alpha)_{\mathrm{PV}}-F_{\mathrm{R}} U_{\mathrm{L}} \frac{T_{\mathrm{in}}-T_{\mathrm{a}}}{I_{\mathrm{t}}},
$$

where $\eta_{\mathrm{th}}$ is the thermal efficiency of the PVT collector, $q_{\mathrm{u}}$ is the useful thermal energy extracted $\left(\mathrm{W} / \mathrm{m}^{2}\right), I_{\mathrm{t}}$ is the total solar irradiance per meter square $\left(\mathrm{W} / \mathrm{m}^{2}\right),(\tau \alpha)_{\mathrm{PV}}$ is the combined transmittance-absorptance coefficient, $T_{\text {in }}$ is the inlet water temperature and $T_{\mathrm{a}}$ is the ambient temperature.

In the ISO method, the collector is also tested under steady-state conditions but in this case the difference between the mean fluid temperatures $\left(T_{\mathrm{fm}}\right)$ and ambient temperatures $\left(T_{\mathrm{a}}\right)$ is considered $[9,13,29]$,

$$
\begin{gathered}
\eta_{\mathrm{th}}=\frac{q_{\mathrm{u}}}{I_{\mathrm{t}}}=\eta_{\mathrm{o}}-a_{1} T_{\mathrm{r}}-a_{2} I_{\mathrm{t}} T_{\mathrm{r}}^{2}, \\
T_{\mathrm{r}}=\frac{T_{\mathrm{fm}}-T_{\mathrm{a}}}{I_{\mathrm{t}}},
\end{gathered}
$$

where $\eta_{\mathrm{o}}$ is the optical efficiency, $a_{1}$ is the heat-loss coefficient which accounts for the linear heat-loss variation, 
$a_{2}$ is the temperature dependence of the heat-loss coefficient which accounts for the quadratic heat loss variation, $T_{\mathrm{fm}}$ is the mean fluid temperature and $T_{\mathrm{r}}$ is the reduced temperature.

The PV electrical efficiency varies linearly with the cell operating temperature as $[12,26,64,71]$,

$$
\eta_{\mathrm{PV}}=\eta_{\mathrm{ref}}\left[1-\beta_{0}\left(T_{\mathrm{PV}}-T_{\mathrm{ref}}\right)\right],
$$

where $\eta_{\text {ref }}$ is the reference module efficiency at a PV cell temperature, $T_{\text {ref, }}$ of $25^{\circ} \mathrm{C}$ and at a solar irradiance of $1,000 \mathrm{~W} / \mathrm{m}^{2}$ (value given by the manufacturer), and $\beta_{0}$ is the temperature coefficient for the PV module, also given in the technical specifications of the ECOMESH panel being considered.

A parametric analysis with the aim of selecting the most promising design(s) for the two absorberexchanger configurations (sheet-and-tube, flat-box) is also undertaken. A range of pipe diameters and number of riser tubes for a fixed total collector width $(B)$ are investigated for the sheet-and-tube configuration, considering both copper and aluminium as material, and a range of polymeric materials, copper and aluminium as well as different channel dimensions are considered for the flat-box configuration.

\section{$2.2 \quad$ PVT collector parameters}

In this work, the commercial ECOMESH panel [30] is selected as the reference PVT collector. Similarly to Figure 1, this collector comprises (from top to bottom): i) a transparent glass cover and insulating gas layer [29], ii) a multi-crystalline silicon PV module, iii) an EVA encapsulating film, iv) an absorber-exchanger which transfers heat to the heat transfer fluid, and v) an insulation layer. The absorber-exchanger consists of a sheetand-tube heat exchanger in which the heat transfer fluid (water) flows through nine parallel copper pipes. The external diameter of the pipes is $8 \mathrm{~mm}$ and the thermal conductivity is $400 \mathrm{~W} /(\mathrm{m} \cdot \mathrm{K})$ [13]. The PVT collector has a nominal (peak) electrical power of $240 \mathrm{~W}_{\mathrm{p}}$, total aperture area of $1.5 \mathrm{~m}^{2}$, nominal PV module efficiency of $14.7 \%$, and a PV temperature coefficient of $-0.45 \% / \mathrm{K}$. The recommended collector flow-rate range is 10 $50 \mathrm{~L} / \mathrm{h}$, with $30 \mathrm{~L} / \mathrm{h}$ taken as the nominal value [30]. In the present work, all PVT collector parameters relating to its different layers are kept constant (dimensions, cover layers, PV cells, etc.), only varying the parameters associated with the absorber-exchanger, for comparison purposes.

As a first alternative to the reference case, considering the results of the parametric analysis in Section 3.2, six different copper sheet-and-tube designs are studied, with three different riser-tube diameters $(6,8$ and $10 \mathrm{~mm}$ ) and three different number of riser tubes (9,12 and 18 tubes). Additionally, to study the influence of the material on the performance of the PVT collector, four of the previous sheet-and-tube designs are modelled using aluminium alloy as the solid material (see Table 1, which summarises all the different design materials and dimensions considered in the present research).

Table 1. Summary of the absorber-exchanger designs studied. Here, $D$ refers to external diameter and $n$ to the number of riser pipes/channels. It should be noted that all designs have an aperture area of $0.948 \times 1.58 \mathrm{~m}$ (PVT collector width $\times$ length), and that the thickness of the absorber plate is $0.5 \mathrm{~mm}$ in the $S \& T$ configuration and $1 \mathrm{~mm}$ in the flat-box configuration.

\begin{tabular}{l|l|l|l|l|l}
\multicolumn{2}{c|}{ Sheet-and-tube } & \multicolumn{4}{c}{ Flat-box structure } \\
\hline \multicolumn{1}{c|}{ Copper } & \multicolumn{1}{c|}{ Aluminium } & Copper & Aluminium & \multicolumn{2}{c}{ Polymer } \\
\hline $\boldsymbol{D}=\mathbf{8} \mathrm{mm}, \boldsymbol{n}=\mathbf{9}^{*}$ & $D=8 \mathrm{~mm}, n=9$ & $3 \times 2 \mathrm{~mm}$ & $3 \times 2 \mathrm{~mm}$ & PC & PA90-15 \\
$D=6 \mathrm{~mm}, n=9$ & $D=10 \mathrm{~mm}, n=9$ & $10 \times 10 \mathrm{~mm}$ & $10 \times 10 \mathrm{~mm}$ & $-3 \times 2 \mathrm{~mm}$ & $-10 \times 10 \mathrm{~mm}$ \\
$D=10 \mathrm{~mm}, n=9$ & $D=8 \mathrm{~mm}, n=12$ & & $20 \times 10 \mathrm{~mm}$ & $-6 \times 4 \mathrm{~mm}$ & PA30-33 \\
$D=8 \mathrm{~mm}, n=12$ & $D=10 \mathrm{~mm}, n=12$ & & & $-10 \times 10 \mathrm{~mm}$ & $-3 \times 2 \mathrm{~mm}$ \\
$D=10 \mathrm{~mm}, n=12$ & & & & PA & $-6 \times 4 \mathrm{~mm}$ \\
$D=8 \mathrm{~mm}, n=18$ & & & $-10 \times 10 \mathrm{~mm}$ & $-10 \times 10 \mathrm{~mm}$ \\
& & & & $-20 \times 10 \mathrm{~mm}$ & $-20 \times 10 \mathrm{~mm}$ \\
& & & & $-40 \times 10 \mathrm{~mm}$ & $-40 \times 10 \mathrm{~mm}$
\end{tabular}

* Reference case is highlighted in bold. 
As shown in Table 1, a number of different flat-box designs have been considered in this work as potential alternatives to the sheet-and-tube configuration. In particular, 5 channel dimensions are studied, i.e.: $20 \times 10 \mathrm{~mm}\left(W_{\mathrm{b}} \times H_{\mathrm{b}}\right)$ as suggested by previous authors [25,72,73], $10 \times 10 \mathrm{~mm}$ as suggested in Ref. [33], $6 \times 4$ $\mathrm{mm}$ as studied in Ref. [36], and two additional dimensions: $40 \times 10 \mathrm{~mm}$ and $3 \times 2 \mathrm{~mm}$, not analysed before to the best knowledge of the authors. Different materials are also assessed for the absorber-exchanger, copper, aluminium alloy and two polymer types: PC and PA. Some variations of the latter with different loadings of hexagonal boron nitride (hBN) particles (additive) have also been studied [37]. The physical and mechanical properties of the different proposed materials are summarised in Table 2. More details of the different design features can be found in Table B.1 in Appendix B.

Table 2. Physical and mechanical properties of the different materials considered.

\begin{tabular}{|c|c|c|c|c|c|c|c|c|}
\hline Properties & 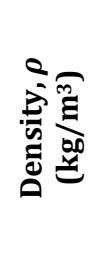 & 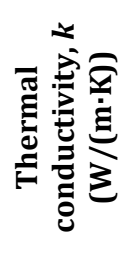 & 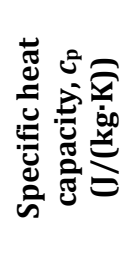 & 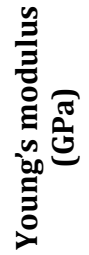 & 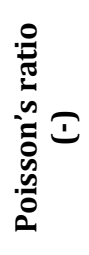 & 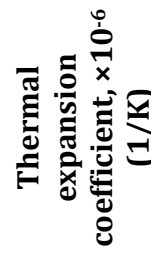 & 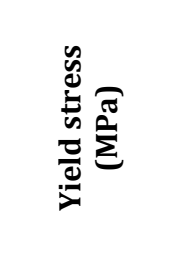 & 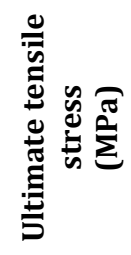 \\
\hline Tempered Glass ${ }^{1}$ & 2,210 & 1.40 & 730 & 70 & 0.22 & 9 & $750-2,130$ & 180 \\
\hline $\mathrm{EVA}^{2}$ & 960 & 0.35 & 2,090 & 0.018 & 0.32 & 350 & - & 26 \\
\hline Tedlar ${ }^{3}$ & 1,250 & 0.36 & 1,200 & 2.34 & 0.40 & 75 & 38 & $55-110$ \\
\hline PV module (silicon) ${ }^{4}$ & 2,329 & 130 & 700 & 170 & 0.28 & 2.6 & $3,200-3,460$ & $160-180$ \\
\hline Copper 5 & 8,700 & 400 & 385 & 110 & 0.35 & 17 & 230 & 287 \\
\hline Aluminium alloy 4 & 2,702 & 237 & 903 & 75 & 0.33 & 22 & 265 & 300 \\
\hline $\mathrm{PC}^{6}$ & 1,180 & 0.78 & 1,200 & 2.35 & 0.38 & 68 & $59-70$ & $55-75$ \\
\hline PA30-337 & 1,390 & 3.60 & $1,700^{+}$ & 2.9 & 0.36 & 51 & $50-95$ & $90-165$ \\
\hline PA & 1,140 & 0.26 & $1,700^{+}$ & $\mathrm{N} / \mathrm{A}$ & $\mathrm{N} / \mathrm{A}$ & $\mathrm{N} / \mathrm{A}$ & $\mathrm{N} / \mathrm{A}$ & $\mathrm{N} / \mathrm{A}$ \\
\hline PA90-157 & 1,170 & 1.20 & $1,700^{+}$ & $\mathrm{N} / \mathrm{A}$ & $\mathrm{N} / \mathrm{A}$ & $\mathrm{N} / \mathrm{A}$ & $\mathrm{N} / \mathrm{A}$ & $\mathrm{N} / \mathrm{A}$ \\
\hline
\end{tabular}

${ }^{1}[74] ;{ }^{2}[75] ;{ }^{3}[76] ;{ }^{4}[77] ; 5^{5}[78] ;{ }^{6}[79] ; 7^{7}[37]$.

${ }^{+}$The same heat capacity is considered for all PAs as the addition of $h B N$ does not significantly influence this physical property and its effect on the absorber-exchanger performance (within this order of magnitude) is negligible.

The same initial conditions are applied to all considered PVT collector designs at steady state, i.e.: a total incident solar irradiance $\left(I_{\mathrm{t}}\right)$ of $1000 \mathrm{~W} / \mathrm{m}^{2}$, ambient temperature $\left(T_{\mathrm{a}}\right)$ of $25^{\circ} \mathrm{C}$, mains water temperature $\left(T_{\text {in }}\right)$ of $20^{\circ} \mathrm{C}$, and PVT collector tilt angle $(\theta)$ of $35^{\circ}$, which corresponds to the tilt angle which maximises the annual energy generation in cities such as Pekin, New York, Rome or Madrid. It should be noted that two collector flow-rates are considered: a nominal flow-rate specified by the PVT manufacturer of the reference PVT collector, $30 \mathrm{~L} / \mathrm{h}\left(8.3 \times 10^{-3} \mathrm{~kg} / \mathrm{s}\right)$, which is used for all sheet-and-tube configurations, and the optimal flowrate for the $10 \times 10 \mathrm{~mm}$ flat-box configuration according to Refs. [33,34], $19.2 \mathrm{~L} / \mathrm{h}\left(5.3 \times 10^{-3} \mathrm{~kg} / \mathrm{s}\right)$, which is used for all flat-box designs. Furthermore, the latter optimal flow-rate is also considered in the reference PVT collector to compare it with the flat-box alternatives under the same operating conditions.

\section{$2.3 \quad$ Structural analysis}

To complement the aforementioned analysis, 3-D CFD-FEM modelling is used and solid mechanics is added to undertake a structural analysis of the most promising absorber-exchanger designs. As discussed previously, the significant amount of both time and computational resources required for detailed 3-D CFD-FEM simulations makes it necessary to apply some simplifications to simplify the problem (even though this slightly reduces the accuracy of the 3-D model, as discussed below). As stated previously, only two channels are modelled (in the flat-box configurations), reducing significantly the computational time and resources. To verify that the number of modelled channels does not influence the results, simulations were run with 2, 5, 10, 15 and 20 channels, obtaining the same results (within numerical error), when the same boundary conditions were applied.

For the structural analysis, additional boundary conditions and constraints are required to specify how the collector is held within its frame and overall structure. It is assumed that the collector is completely fixed 
with its frame at the collector water inlet, while at the collector water outlet the frame has some tolerance, allowing expansion in the flow direction ( $y$-direction) and along its width ( $x$-direction) but not allowing displacement along its height (z-direction); see Figure 3. More details can be found in Appendix A.

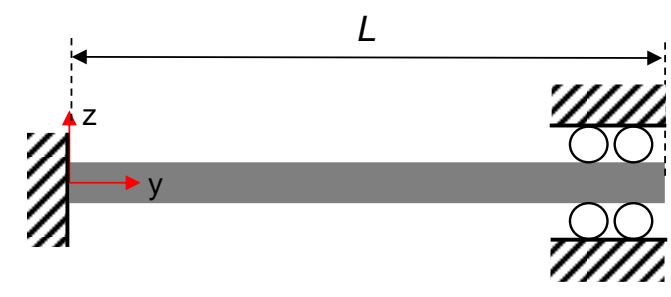

Figure 3. Sketch of the PVT collector (length L) inlet (fixed) and outlet (prescribed displacement) supports.

Due to the possible reduced accuracy expected from the introduction of the above modelling simplification (i.e., modelling two channels), a full 3-D analysis was also undertaken in order to understand the limits of the simplified model. The 3-D analysis demonstrated that, when considering the full 3-D problem, the maximum stresses suffered by the PVT collector are lower than those obtained above, which can be used as conservative limits. To this end, the cover glass was selected for closer inspection, since this is the layer with smaller temperature gradient and therefore smaller thermal expansion, which, as it will be shown later, leads to a reduction in stresses and therefore material issues. It is also the layer that experiences the highest stresses due to its weight, and thus the one most affected by the boundary conditions set on the lateral sides as shown below. Thus, the whole cover glass $(0.948 \times 1.58 \mathrm{~m})$ was modelled: i) with the lateral sides supported (i.e., set with a prescribed displacement) in order to model the case when this is held by the PVT frame (Figure 4 top), and ii) with the lateral sides unsupported (i.e., let free, displacement is allowed), as it is considered when modelling two channels (Figure 4 bottom).

The von Mises stress criterion (also called the equivalent or effective stress) [80-82] is used to evaluate whether the various PVT layers will yield when subjected to the strains associated with thermal expansion in normal operating conditions. The von Mises stress criterion can be formulated as indicated in Eq. (5), and it can be defined as the driving force for damage in many ductile engineering materials:

$$
\sigma_{\mathrm{M}}=\sqrt{\frac{1}{2} \cdot\left[\left(\sigma_{x}-\sigma_{y}\right)^{2}+\left(\sigma_{x}-\sigma_{z}\right)^{2}+\left(\sigma_{y}-\sigma_{z}\right)^{2}+6 \cdot\left(\tau_{x y}+\tau_{y z}+\tau_{x z}\right)\right]} .
$$

The von Mises stress is routinely computed by COMSOL, and it is compared to the material's yield stress (or to the Ultimate Tensile Stress, UTS, when it is lower than the former, see Table 2), to determine whether each layer would yield or fracture. The maximum displacement due to deformation that the PVT collector suffers is also analysed; in this case this is defined as the percentage of the maximum displacement suffered by the collector over the total collector length.

The results for the cover glass analysis show that the effective stress suffered (von Mises stress) in the former case (i), more realistic, are significantly lower than in the second one (ii), being the maximum stress allocated on the same zone (see Figure 4 left), that is, the PVT collector water inlet, where the layers are fixed with the frame (left side of the Figure 3). Similarly, the largest displacement occurs in the $z$-direction due to the glass weight, being significantly higher, as expected, when the lateral sides are set free (see Figure 4 right). Therefore, the study undertaken in the present research is conservative in a way that it is expected that if the stresses obtained in the simulations are below the material limits, one could claim that the whole PVT collector will suffer less stresses than the ones shown in this work, so the designs proposed will perform correctly under the limits.

Consequently, and based on the results that showed that the dominant thermal expansion and associated stresses are expected in the $y$-/flow-direction due to the temperature gradient and in the $z$-direction due to gravity, the structural analysis of the PVT collector is simplified into a 2-D problem in the $y$-z plane. 


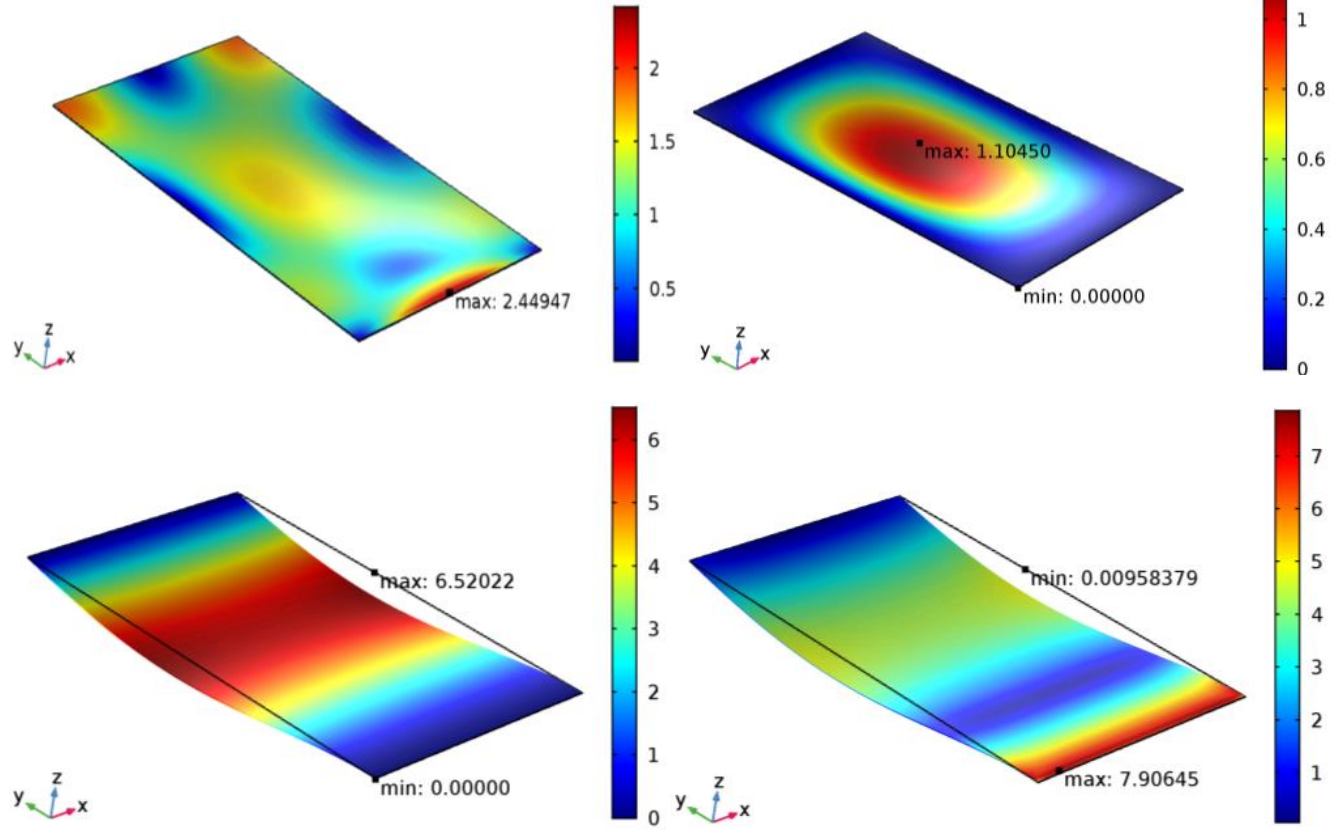

Figure 4. Whole cover glass $(0.948 \times 1.58 \mathrm{~m})$ with the lateral sides: (Top figures) set with prescribed displacement ( $z$ displacement is not allowed but $x$ and $y$ displacement is allowed, COMSOL constraint: prescribed displacement); (bottom figures) let free, (displacement is allowed, COMSOL constraint: free). Figures on the left show von Mises stress (MPa), and on the right total displacement (mm).

\section{$2.4 \quad$ Economic analysis}

In order to undertake a simple cost analysis, the investment cost of each PVT collector design is estimated, and the financial benefits (savings) from the electricity and heat generation are converted to the same unit (€/h per PVT collector) and summed. To this end, the electricity and natural gas prices should be considered, whose corresponding values $(€ / \mathrm{kWh})$, in Spain, at the time of the research, are shown in Table 3, along with the prices of the materials and production costs of the proposed absorber-exchanger designs. The selected natural gas and electricity prices are within the range of EU utility prices [83] and thus the results can be generalised to any country or region with similar values.

Table 3. Cost factors used for the economic analysis for the case of Spain.

\begin{tabular}{lcc}
\hline Cost analysis & Value & \\
\hline Natural gas price & $0.05^{+}$ & $€ / \mathrm{kWh}$ \\
Electricity price & $0.14^{+}$ & $€ / \mathrm{kWh}$ \\
Polymer cost & $2.3-3.0^{*}$ & $€ / \mathrm{kg}$ \\
Additive $(\mathrm{hBN})$ cost & $150 \dagger$ & $€ / \mathrm{kg}$ \\
Aluminium $20 \times 10$ mm flat-box cost & 2.33 & $€ / \mathrm{m}$ \\
Ratio copper/aluminium cost & 1.27 & - \\
Extrusion production cost & 2 & $€ / \mathrm{m}$ \\
\hline
\end{tabular}

* Price varies slightly between this range for PA, PA30, PA90 and PC; + Refs. [84,85]; † Personal communications [86,87]

The economic analysis presented here aims to estimate the payback time (PBT) of the collectors based on their investment costs $\left(C_{0}\right)$ and cost savings (in $€ /$ h per PVT collector) as detailed in Eq. (6). Only capital costs are considered, without including transport or installation costs. For the PBT estimation, the same weather and operating conditions (as detailed in Section 3.2) are considered in all cases, thus leading to a simple figure that can be used for the intended comparison. The investment cost of the polymeric absorber-exchanger design is estimated from the cost of the raw material and the cost of adding the additive (hBN), where this is applicable, and also includes an estimation of the extrusion production cost. 
For the aluminium designs, the price of off-the-shelf square-channel tubes is considered [88], which is then extrapolated to the copper square channels considering the price ratio of both materials (Table 3 ).

$$
P B T(\text { days })=\frac{C_{0}(€)}{\text { cost savings }(€ / \mathrm{h}) \cdot 24(\mathrm{~h} / \text { day })} .
$$

\section{Results and Discussion}

The 3-D CFD-FEM model of the reference PVT collector is first validated against experimental data provided by the manufacturer in Section 3.1.2. It is emphasised, as noted earlier, that the PV electrical power output is also modelled and reported (see Figure 15), but our main focus is on the collectors' thermal performance so details on the electrical efficiency are only provided in the final analysis (see Section 3.5). The thermal efficiency, $\eta_{\mathrm{th}}$, is plotted against the reduced temperature $T_{\mathrm{r}}$, to obtain the coefficients $\eta_{0}, a_{1}$ and $a_{2}$ in Eq. (2) via data fitting. Mesh validation is then performed in order to find the optimal mesh for the 3-D CFD-FEM problem, aiming to reduce the computational time and resources as much as possible without losing accuracy in the results. Section 3.2 summarises the results of the parametric analysis undertaken for different pipe diameters in the sheet-and-tube design, which leads to the selection and more detailed study of a few potential designs that promise improved performance relative to the reference case. Efficiency curves obtained for selected absorber-exchanger designs are analysed in Section 3.3, followed by a structural analysis of a number of representative collectors in Section 3.4. Finally, results from a technoeconomic comparison of all proposed collector designs are discussed in Section 3.5.

\subsection{Model validation}

\subsubsection{Mesh independence}

In order to optimise the computational effort and time required for the flat-box structure simulations, a mapped mesh for the cross section of the PVT channels ( $x$ - $z$ plane) was selected, which takes advantage of the rectangular shape of the mesh elements. In a first approach, a simple uniform mesh was applied ("NBL $=0$ " in Figure 5). The mesh was then refined in the fluid domain inside the channel by adding points and also grid non-uniformity to capture the velocity gradients and the associated convective heat transfer from the surface of the solid into the fluid. As shown in Figure 5 (left), as the "Number of Boundary Layers" (NBL) in COMSOL was increased, more elements were added in the fluid domain, with smaller elements close to the surface and larger ones in the channel centre. The heat flux $\left(\mathrm{W} / \mathrm{m}^{2}\right)$ into the liquid from the top of the channel (red line) for each of the studied meshes is shown in Figure 5 (right). The results show a deviation of less than $0.3 \%$ in all cases, with convergence from $N B L>8$. The $N B L=0$ mesh results were the same as those for $N B L=4$, with a deviation of less than $0.1 \%$ relative to $N B L>8$. Based on these results, and the significantly reduced computational resources required, it was decided to use the simplest mesh $(N B L=0)$ for this work (around 5 times faster than $N B L=8$, with less than $1 / 3$ of the RAM requirements).

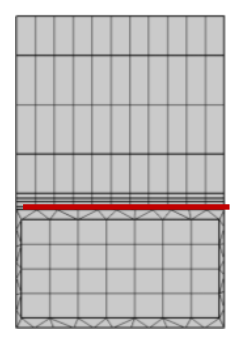

$N B L=0$

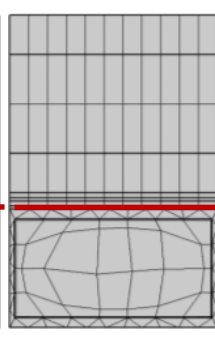

$N B L=1$

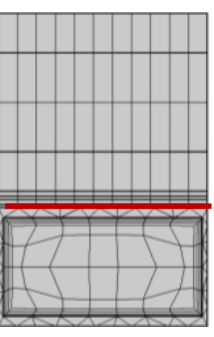

$N B L=4$

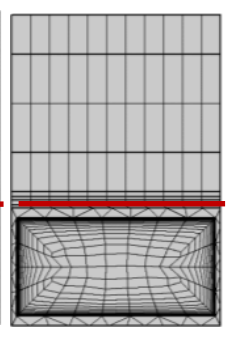

$N B L=16$

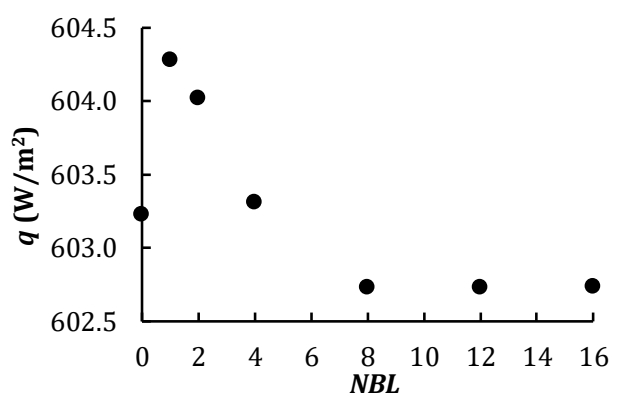

Figure 5. Mesh convergence for the 3-D flat-box structure model: (left) NBL $=$ Number of Boundary Layers, and (right) corresponding $q=$ heat flux $\left(\mathrm{W} / \mathrm{m}^{2}\right)$ through the top of the channel (horizontal red line on left). 


\subsubsection{Performance curves from the 3-D model}

The 3-D CFD-FEM model developed in COMSOL is validated here against the manufacturer's experimentally-derived collector performance curve. To this end, the heat transfer problem was solved for the same ambient conditions (irradiance, wind speed, ambient temperature) and operating conditions (flow-rate, inlet fluid temperature) as specified in the manufacturer test report. The experimental data were obtained by testing the collector in steady-state conditions according to the international standards for solar collector testing EN 12975-2, as described in Ref. [58]. The collector's thermal efficiency $\left(\eta_{\text {th }}\right)$ is plotted in Figure 6 against the reduced temperature $\left(T_{\mathrm{r}}\right)$.

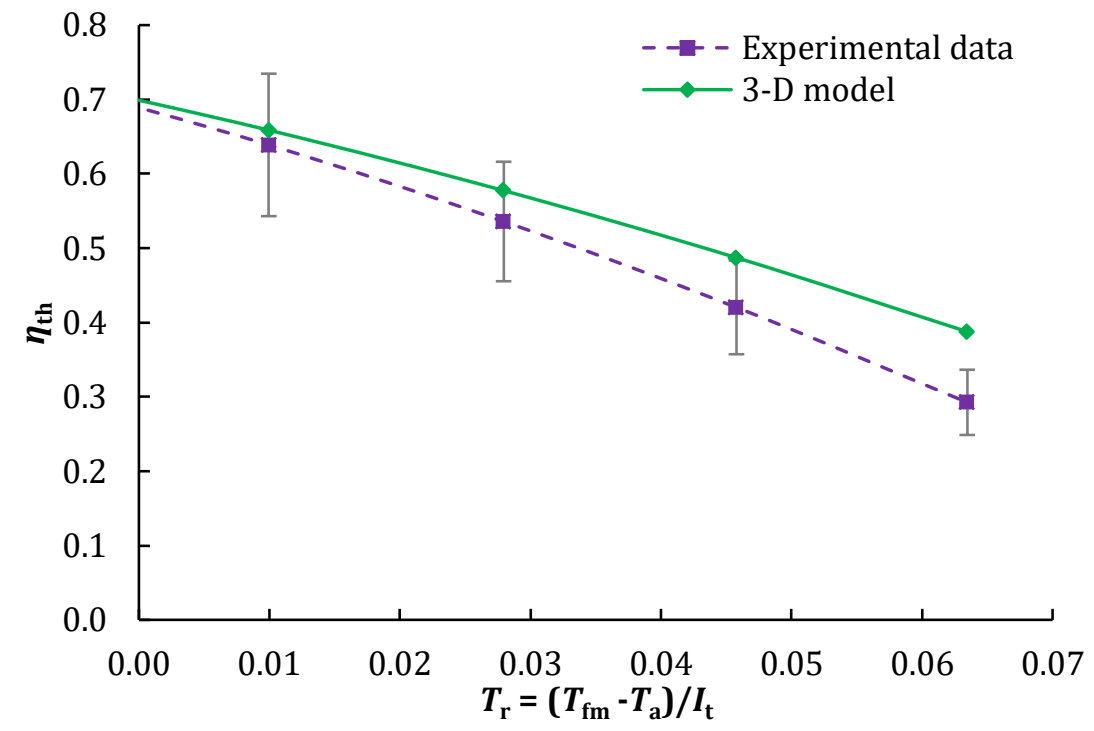

Figure 6. Performance curves of the reference PVT collector for the 3-D model and for the commercial ECOMESH panel (specifications sheet) [30]. Results reproduced from previous work [65] and generated based on the conditions stated in Section 2.2.

The 3-D model fits the experimental results with an average absolute deviation (AAD) of 12\%, over an inlet water temperature range of $0-80^{\circ} \mathrm{C}$. For inlet water temperatures below $60^{\circ} \mathrm{C}$, the AAD error is less than $15 \%$ (error bars in Figure 6), while the largest deviations (worst case 25\%) appear at higher operation temperatures. This performance overestimation can be attributed to an underestimation of heat losses in the model, since the model assumes a perfect thermal contact between the PV cells and the rear copper sheet, and between the absorber and the pipe to which it is bonded. It is worth mentioning that previous studies [89] already reported that a poor contact between the PV module and the thermal absorber, leading to an insulating air gap between the layers, can reduce the thermal performance of the collector by up to $30 \%$. Furthermore, heat conduction from the copper absorber to the tubes is modelled as a uniform bond made of copper with fixed dimensions along the entire length of the pipe, whereas in a real collector, and depending on the bonding method (welding, ultrasonic, etc.), this bond will vary. The material and dimensions of the bond strongly affect the heat conduction between the relevant layers and, therefore, the overall collector efficiency [90], as these two factors influence the heat removal factor $\left(F_{\mathrm{R}}\right)$ and overall heat-loss coefficient $\left(U_{\mathrm{L}}\right)$, and thus the PVT collector performance curve. In addition, lateral and edge losses have not been considered here. Finally, it should be noted that the experimental performance curve is obtained from a scatter of experimental points, which might also result in some deviations of the reported curve from the range of actual experimental performance results.

\subsection{Parametric analysis}

As an alternative to the reference collector, various sheet-and-tube designs were studied in an attempt to improve the efficiency of the PVT collector. To this end, a series of parametric analyses were performed for 5 different pipe diameters $(D=6,8,10,12$ and $15 \mathrm{~mm})$, varying the number of riser tubes $(n)$ from 2 to 60 pipes for a fixed total collector width $(B=945 \mathrm{~mm})$, equal to that of the reference collector, hence varying the fin width $(W)$ accordingly. The resulting $W / D$ ratio varied from 1 to 80 . 
Figure 7 (left) shows that the pipe diameter $D$ does not influence the thermal efficiency of the PVT collector, whereas an increase in the number of riser tubes $n$ significantly increases both the thermal and electrical efficiencies up to about $n=20-30$, beyond which the efficiency asymptotes, while the weight and cost of the PVT collector continues to increase, as is demonstrated in Section 3.5. This improvement is attributed to the cooling of the absorber and PV plates, allowing more heat to be extracted, which increases the thermal efficiency, while also reducing the maximum PV cell temperature reached between two adjacent pipes, therefore increasing the electrical efficiency. However, from around 20 riser pipes onwards the thermal and electrical efficiencies barely increase (see Figure 7 (right)), so it can be concluded that the slight improvement achieved at even larger $n$ does not outweigh the associated increase in weight and cost. This result confirms the finding in Refs. [36,91,92], where a higher convective heat transfer between the coolant and the channels was achieved with reduced diameters and increased number of channels per unit width, leading to a consequent improvement in thermal efficiency, and also explains why the typical pipe width to pipe diameter ratios found in most sheet-and-tube collectors lies in the range 6-10 [36].
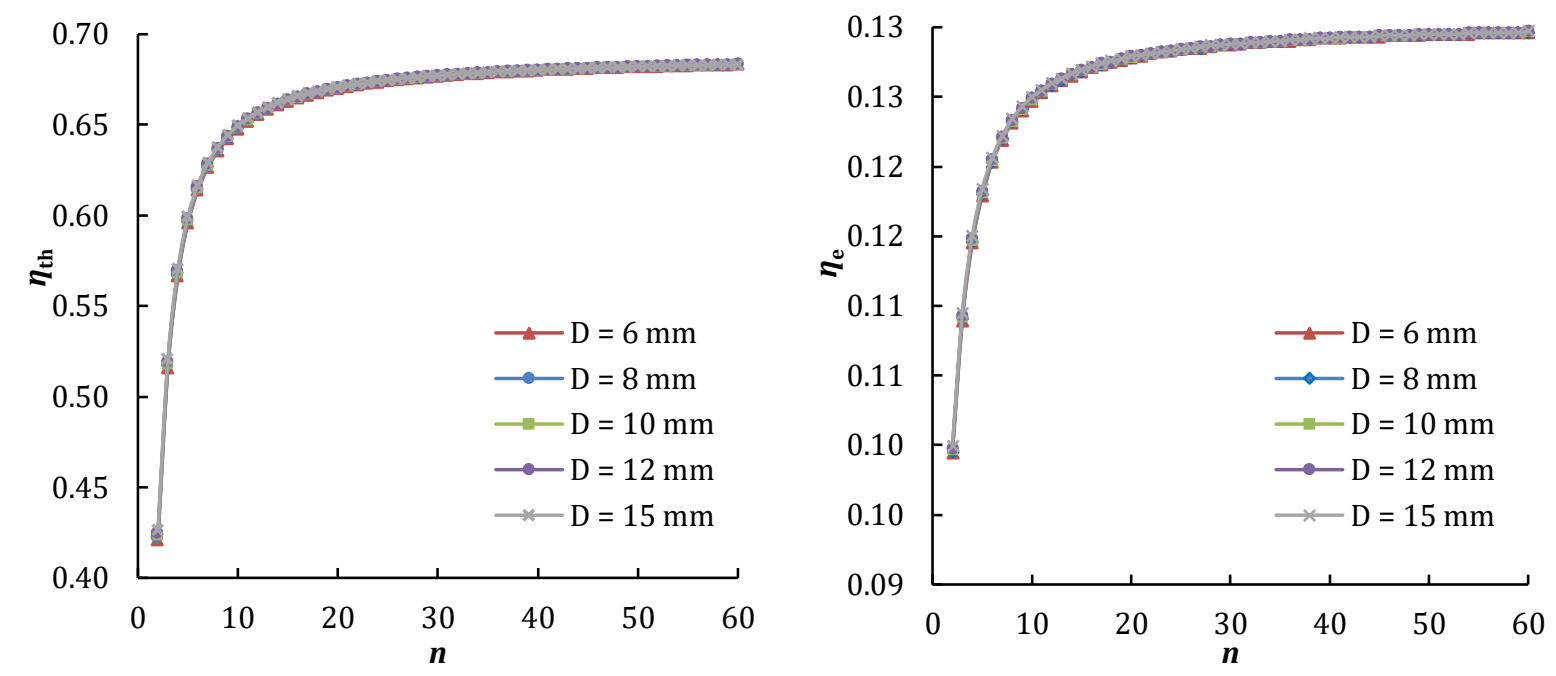

Figure 7. Effect of the number of riser tubes $n$ on: (left) thermal efficiency $\eta_{\text {th }}$ and (right) electrical efficiency $\eta_{\mathrm{e}}$ for different riser tube diameters D. Results generated based on the conditions stated in Section 2.2.

Bearing in mind these results, performance curves for the following selected PVT collector designs were obtained by the detailed 3-D model in order to examine and compare their relative performance:

- For $n=9: D=6,8$ and $10 \mathrm{~mm}$ - to study the influence of the pipe diameter;

- For $D=8 \mathrm{~mm}: n=9,12$ and 18 - to study the influence of the number of pipes;

- For $D=10 \mathrm{~mm}: n=12$ - to confirm that the previous results also apply to a larger pipe diameter.

\subsection{Performance curve analysis}

Both the ASHRAE and ISO methods detailed in Section 2.1 were considered when comparing the thermal performance of the selected designs. As shown in Figure 8, similar results are obtained with both methods, so it was decided to use the ISO method (Figure 8 (left)) to compare the different designs, also because the ISO curves are less dependent on the collector flow-rate due to the fact that this method employs the reduced temperature $\left(T_{\mathrm{r}}\right)$ that varies according to the flow-rate, as opposed to ASHRAE that only considers the inlet water $\left(T_{\text {in }}\right)$ and ambient $\left(T_{\mathrm{a}}\right)$ temperatures such that different thermal efficiency curves are obtained for different flow-rates. The ASHRAE method is still used in this research to determine the heat removal factor $\left(F_{\mathrm{R}}\right)$ and the overall heat-loss coefficient $\left(U_{\mathrm{L}}\right)$ of the studied designs (see Figure 15$)$.

Sheet-and-tube configuration. The thermal efficiency curves as a function of the tube diameter $(D)$ for a number of tubes $(n)$ varying between 9 and 18 are reported in Figure 8. The pipe diameter does not notably influence the thermal efficiency but doubling the number of riser tubes leads to an absolute increase in the thermal efficiency of $1.5 \%$, or a relative increase of $2.3 \%\left(\eta_{\mathrm{th}}=67.4 \%\right.$ for $n=18 v s . \eta_{\mathrm{th}}=$ $65.9 \%$ for $n=9$ for the same conditions, as given in Section 2.2). Similar results are obtained for 
aluminium sheet-and-tube designs (not shown here). For the same design (same $D$ and $n$ ), the copper sheet-and-tube performs better than the aluminium equivalent, as expected, due to the higher thermal conductivity of copper. However, the reduction in price and weight of the aluminium designs may outweigh the very slight decrease in thermal performance of $1.2 \%$ (relative) $\left(\eta_{\text {th }}=65.9 \% v s . \eta_{\text {th }}=65.1 \%\right.$ respectively for $n=9$ and $D=8 \mathrm{~mm}$ with conditions as in Section 2.2) as will be shown in Section 3.5.
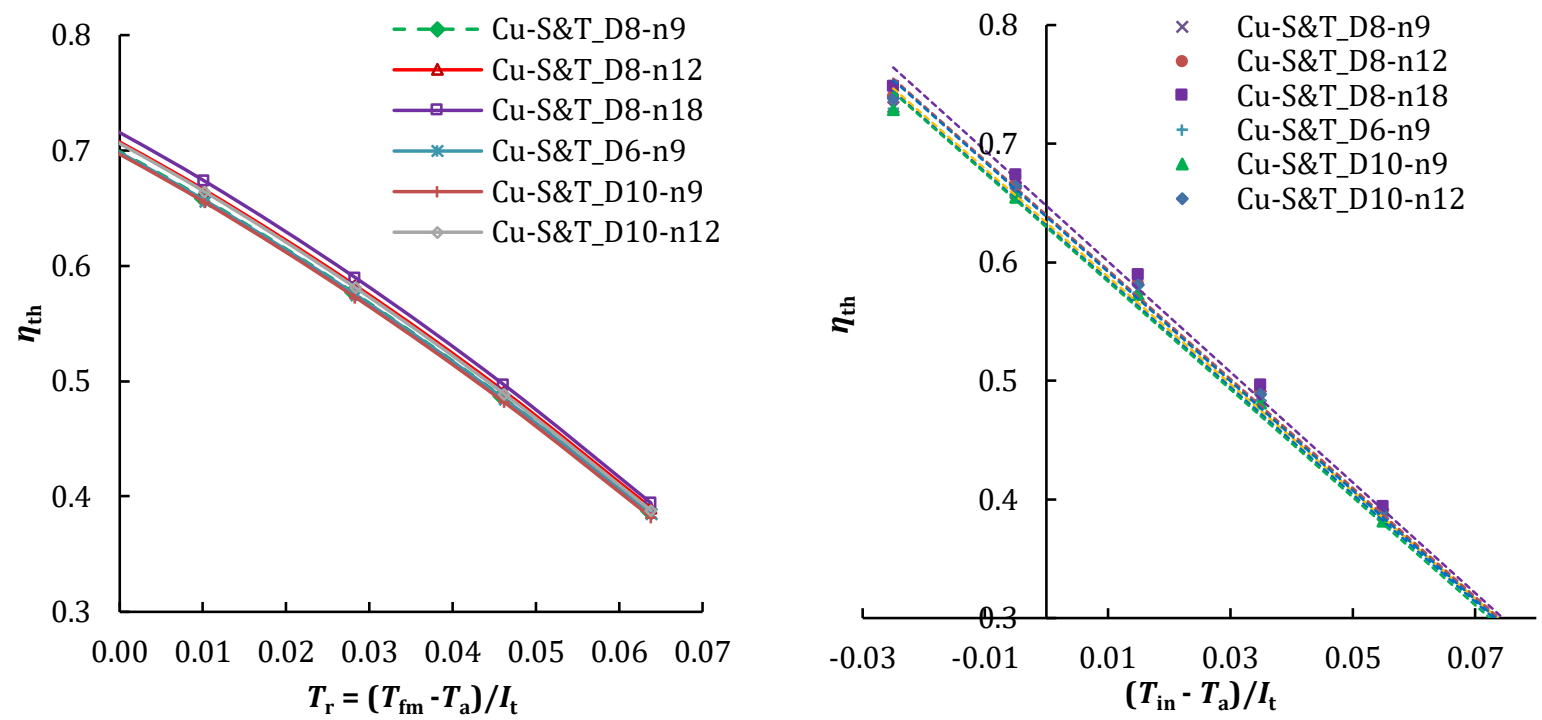

Figure 8. Performance curves of the different copper sheet-and-tube designs studied, considering (left) ISO (Eq. (2)) and (right) ASHRAE (Eq. (1)) methods. In the legend, for example, Cu-S\&T_D8-n9, refers to 9 copper pipes with an external diameter of $8 \mathrm{~mm}$. Results generated based on the conditions stated in Section 2.2.

Flat-box configuration. Various channel dimensions and materials are investigated in conjunction with this collector configuration. A full list of flat-box PVT designs studied in this work is given in Table 1. Irrespective of the material and channel size, all the flat-box designs slightly outperform the reference copper-sheet-and tube design (Figure 9), since the heat transfer area between the absorber plate and the fluid is significantly larger than in the sheet-and-tube design, which outweighs the impact of the lower thermal conductivity of all the polymers considered here. As a consequence, the temperature on the top of the flat-box design is uniform and lower on average compared to the equivalent temperature observed in the sheet-and-tube design, leading to lower thermal losses (top thermal losses for the sheet-and-tube $q_{\text {top }}=144 \mathrm{~W} / \mathrm{m}^{2}$, while for the copper $10 \times 10$ flat-box, $q_{\text {top }}=109 \mathrm{~W} / \mathrm{m}^{2}$ ). This result is in agreement with the results found by previous studies that used polymeric flat-box absorber-exchanger $[33,62]$.

The effect of the flat-box solid construction material on the thermal efficiency of this configuration is assessed for PVT collectors with the same channel dimensions $(10 \times 10 \mathrm{~mm})$ in Figure 9 left. It is observed that the optical efficiency $\left(\eta_{\mathrm{o}}\right)$ is higher by up to $4.3 \%$ and that the heat loss-coefficient $\left(a_{1}\right)$ is lower by up to $15.5 \%$ compared to the sheet-and-tube collector, with the best performance achieved by the $10 \times 10 \mathrm{~mm}$ channel designs. The difference in the performance curves between the best (made of copper) and worst (made of PA) flat-box design is less than 5\% for the same channel dimensions. It should be highlighted the small thickness of the absorber plate $(1 \mathrm{~mm})$, leading to a small solid thermal resistance. Thus, the thermal performance of the PVT collector is less sensitive to the choice of material in this type of collector design.

As can be seen from the results in Figure 9 (right), for the same material, the channel dimensions also do not have a significant influence on the PVT collector thermal efficiency. The results show that the optical efficiency $\left(\eta_{0}\right)$ can be increased by $4.6 \%$, and the heat-loss coefficient $\left(a_{1}\right)$ reduced by $15.5 \%$ relative to the reference case, when employing smaller channels. This is attributed to the higher water velocity through smaller channels given the smaller hydraulic diameters, since the total collector flow-rate is maintained constant in all the cases, which leads to higher convective heat transfer coefficients $\left(h=1110 \mathrm{~W} / \mathrm{m}^{2} \mathrm{~K}\right.$ for the best case $(3 \times 2 \mathrm{~mm}) v \mathrm{~s} . h=170 \mathrm{~W} / \mathrm{m}^{2} \mathrm{~K}$ for the worst case $(40 \times 10 \mathrm{~mm}))$. As a consequence, the temperature difference between the absorber plate $\left(T_{\mathrm{abs}}\right)$ and the fluid mean temperature $\left(T_{\mathrm{fm}}\right)$ is significantly smaller for the smaller channel designs. 

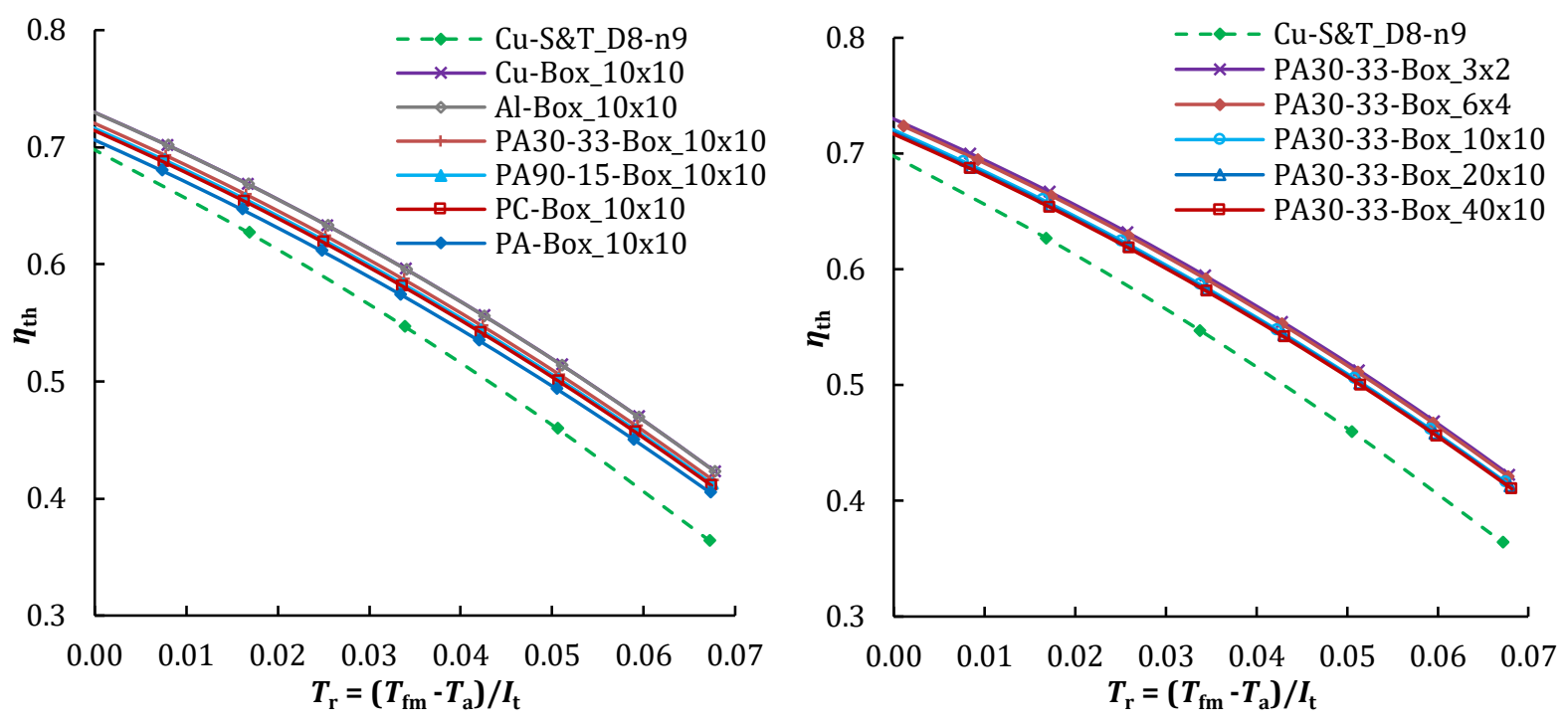

Figure 9. Performance curves of the different PVT designs studied for (left) same dimensions with different materials and (right) same material with different channel dimensions. Results reproduced from previous work [65] and generated based on the conditions stated in Section 2.2.

From the results obtained relating to the flat-box configuration, the most promising PVT designs appear to have channel dimensions of $10 \times 10 \mathrm{~mm}$ or lower. By analysing their efficiency for a range polymeric materials, it can be concluded that the small increase in thermal performance of the PVT collector might not outweigh the higher complexity and costs of loading the polymer with additives. Furthermore, the improvement achieved with the copper flat-box design relative to off-the-shelf polymers (e.g., PC or PA) for the same channel dimensions is small. When bringing into consideration the weight of the PVT collectors achieved with the proposed flat-box designs, Figure 10 shows that all the polymeric flat-box designs achieve a weight reduction of 7-12\% compared to the reference case (Cu-S\&T_D8-n9, red circle in Figure 10), whereas the aluminium flatbox collectors are $2-12 \%$ heavier (blue crosses) and the copper flat-box designs $48 \%(3 \times 2 \mathrm{~mm})$ and $59 \%$ $(10 \times 10 \mathrm{~mm})$ heavier (light blue squares) than the reference collector, respectively. The absorber-exchanger accounts for $17.3 \%$ of the total PVT collector weight in the reference sheet-and-tube collector.

Bearing in mind these results, a structural characterisation as well as a technoeconomic analysis are required to bring into consideration other factors such as thermal expansion and stresses, PVT collector cost and payback time before more definitive conclusions are drawn.

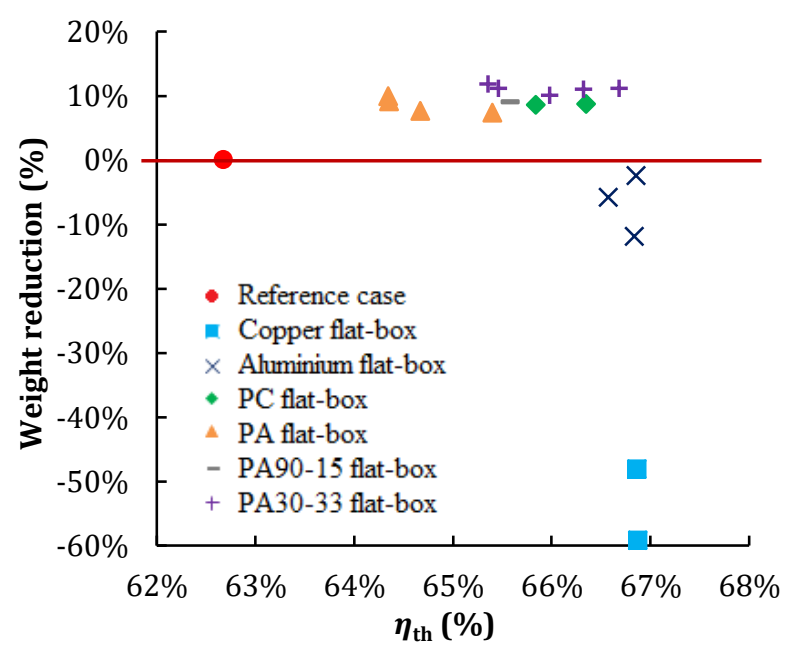

Figure 10. Percentage of weight reduction vs. thermal efficiency of the PVT collector for the different designs of flat-box design studied and the reference S\&T collector. 


\subsection{Structural characterisation of the most promising and representative designs}

This section summarises the structural analysis of the most promising and representative absorber-exchanger designs detailed in Table 4. As detailed in Section 2, the results obtained from the previous multi-physics calculation (e.g., temperature distribution, fluid velocity profiles, heat transfer between the different layer and domains) are fed in a second simulation step to solve the solid mechanics equations.

Table 4. Summary of the absorber-exchanger designs selected for the structural characterisation.

\begin{tabular}{lccc}
\hline Copper & S\&T_D8-n9 & $3 \times 2 \mathrm{~mm}$ & \\
Aluminium & S\&T_D8-n9 & $3 \times 2 \mathrm{~mm}$ & \\
PC & $3 \times 2 \mathrm{~mm}$ & $6 \times 4 \mathrm{~mm}$ & $10 \times 10 \mathrm{~mm}$ \\
PA30-33 & $3 \times 2 \mathrm{~mm}$ & & \\
\hline
\end{tabular}

Figure 11 shows the maximum von Mises stress values for the different layers of the PVT collector designs, providing an overview of which layers are suffering more strains. In addition, the stress distribution throughout different layer surfaces, which allows the identification of critical points, was also obtained, as shown in the following figures.

By comparing the von Mises stress in the different PVT layers with their corresponding yield or UTS, based on the most restrictive value for each particular case, it is possible to conclude that no yield or fracture is expected in any of the layers. For the cover and inner glasses (Glass 1 and Glass 2 respectively), the maximum von Mises stress is lower than $7 \%$ and $19 \%$ of the UTS, respectively (see Figure 11 and Table 2).

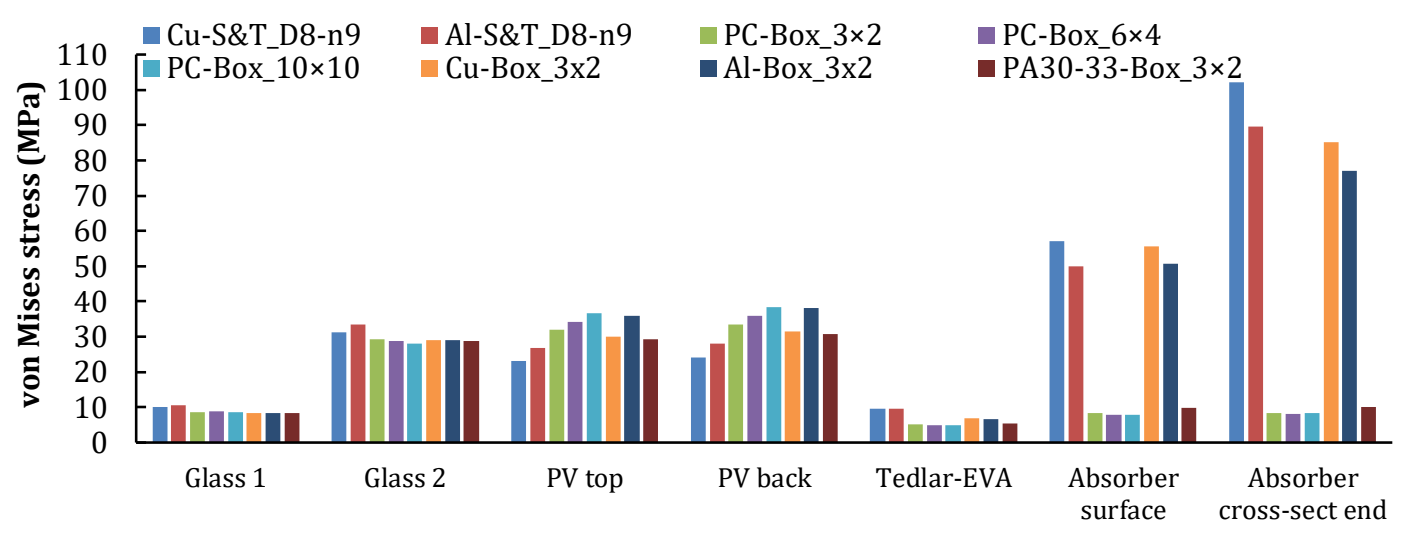

Figure 11. Maximum values of von Mises stress (MPa) for the different layers of the PVT configurations.

In terms of the stress distribution throughout the layers' surfaces, the results show that in all PVT collector configurations, the maximum von Mises stress for Glass 1 occurs at the collector water inlet (see Figure 12 top), which is attributed to its weight effect at the tilted angle. Meanwhile, the maximum value for Glass 2 occurs at the end of the collector, where the maximum thermal expansion occurs, as it is where the higher temperatures are achieved (see Figure 12 bottom).

The maximum von Mises stress in the PV layer is between $14 \%$ to $23 \%$ of its UTS, with the PC $10 \times 10 \mathrm{~mm}$ flatbox design experiencing the highest stress due to a greater thermal expansion suffered in the $z$-direction. It is observed that for the polymeric (PC and PA30-33) flat-box designs, the layer that suffers the highest strains is the PV module, with higher von Mises stress values than for the sheet-and-tube PVT collector (see Figure 11). This is attributed to the larger buckling of the former configurations, especially in the $z$-direction, as shown in Figure 13 right. Specifically, the critical point occurs in a section towards the collector fluid outlet as indicated in Figure 13 (left). It should be noted that the PV layer buckling is the same as for the whole PVT collector since all layers are assumed to be maintained in contact (except for Glass 1) (see Figure 13 right). 

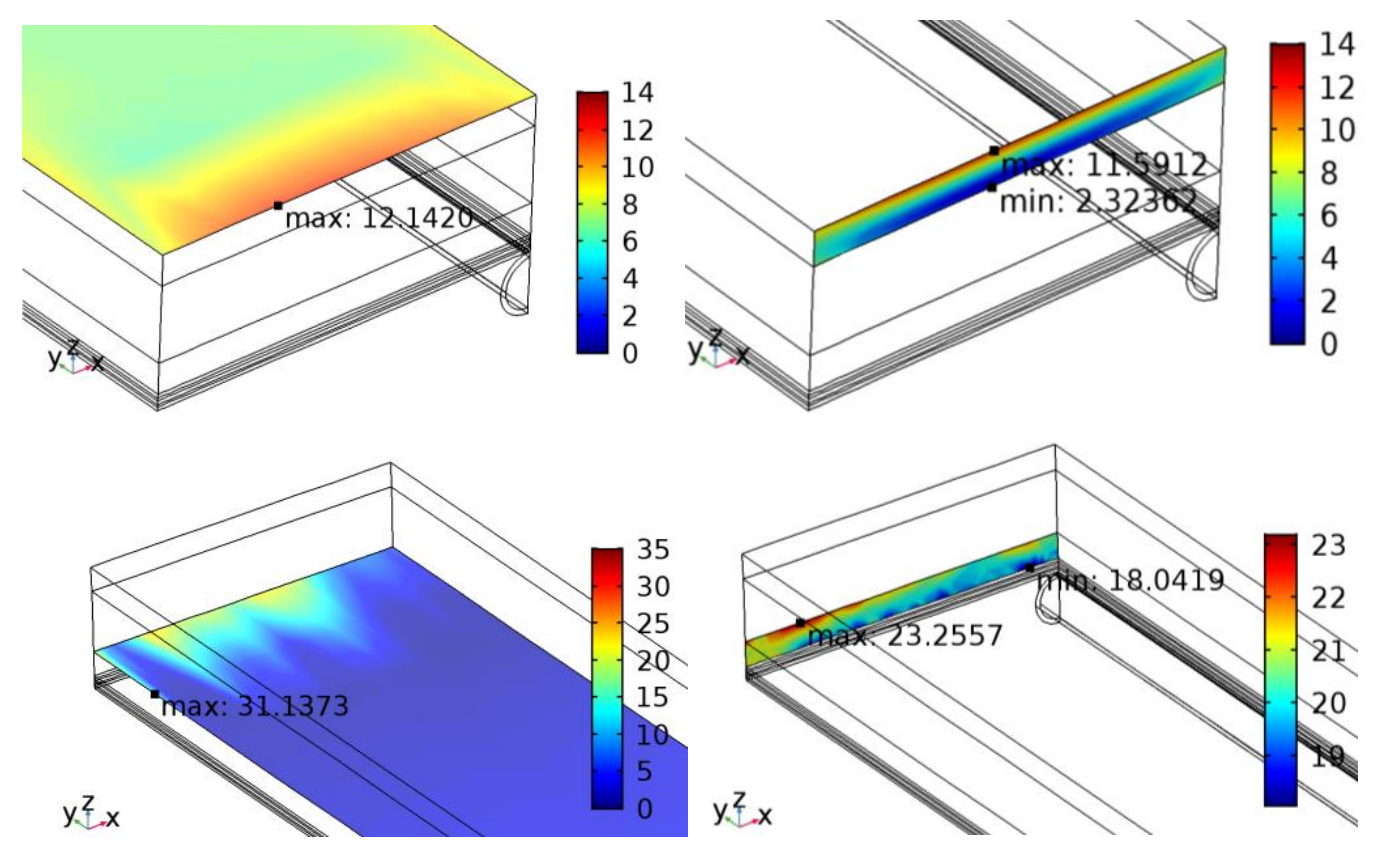

Figure 12. (Top) Von Mises Stress (MPa) for Glass 1 in the (left) upper part, and (right) cross-sectional area at the collector water inlet; (bottom) Von Mises Stress (MPa) for Glass 2 in the (left) upper part, and (right) crosssectional area at the collector outlet, for the sheet-and-tube copper PVT collector.
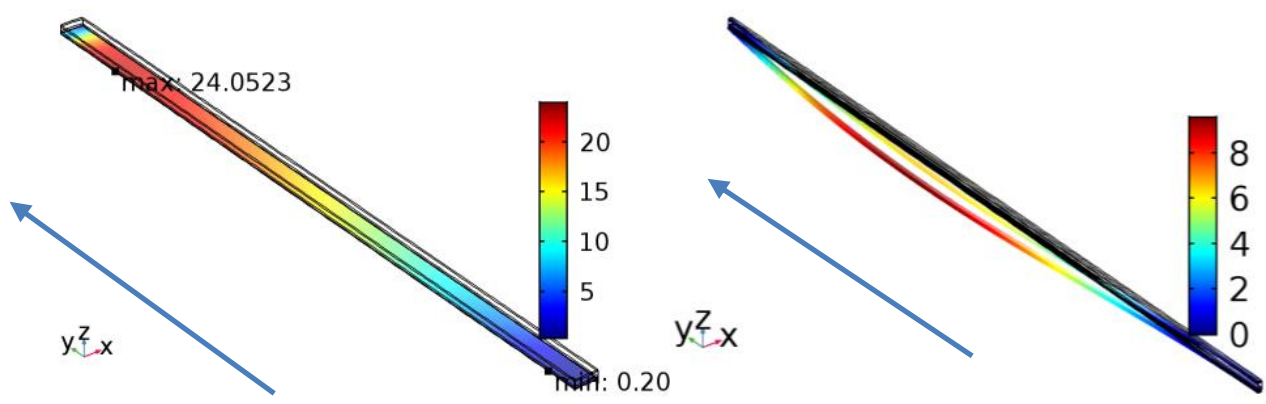

Figure 13. Von Mises Stress (MPa) of the PV layer (left) and thermal expansion of the PVT collector in the z-direction ( $\mathrm{mm}$ ) (right) throughout its length for the PC $3 \times 2 \mathrm{~mm}$ PVT collector. Blue arrow shows the flow direction.

Regarding the variation of the strains for the PC flat-box configurations with different channel dimensions, Figure 11 shows that the von Mises stress increases with the channel dimensions. The thermal expansion that the PVT collector suffers, defined as displacement divided by the total collector length, in percentage, increases as well with channel dimensions, from $0.6 \%$ to $0.8 \%$ displacement in the $z$-direction with respect to the total length, and from $0.04 \%$ to $0.07 \%$ in the $y$-direction)

Finally, concerning the absorber-exchanger, the most critical configuration in terms of strains suffered is the sheet-and-tube collector, in which the maximum von Mises stress is around $64 \%$ and $56 \%$ of the yield stress for the copper and aluminium configurations respectively. The maximum stress occurs in the bonding between the absorber layer and the riser pipe at the collector water outlet. This result is expected since: i) this is the area where the highest temperatures are reached, and ii) stress is concentrated in a very small surface area compared with the rest of the PVT layers. As a consequence, the sheet-and-tube configuration is the one with the highest strains.

It should be noted that the values of the mechanical properties can vary within a wide range depending on the specific copper and aluminium alloys used for the bonding in each case, so more accurate values (provided by the sheet-and-tube collector manufacturer) are necessary for a more detailed structural analysis. In all of the absorber-exchanger flat-box designs, the maximum von Mises stress within the absorber-exchanger is located in the cross-sectional area at the collector outlet (see Figure 14), and amounts to $<37 \%$ of the yield stress of the metal (copper, aluminium) collectors and $<13 \%$ of the yield stress of the polymeric collectors. Additionally, 
as shown in Figure 11, the maximum overall collector strains in the copper and aluminium flat-box configurations occur in the aforementioned absorber-exchanger cross-sectional area at the collector water outlet, together with the maximum thermal expansion in the $y$-direction (see Figure 14).

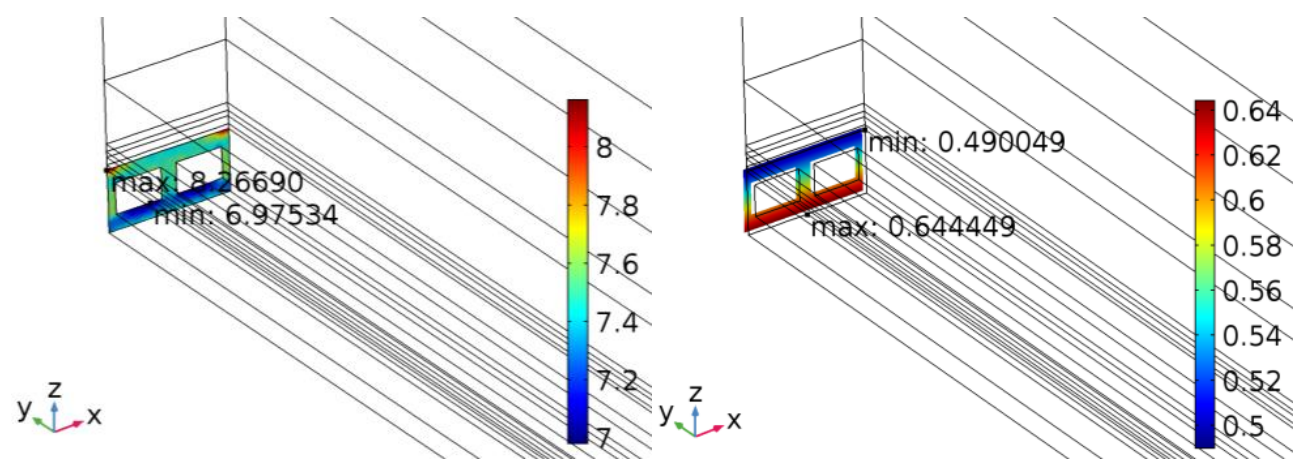

Figure 14. (left) Von Mises stress (MPa) and (right) thermal expansion in the y-direction (mm) over the crosssectional area of the absorber-exchanger for the PC flat-box $3 \times 2 \mathrm{~mm}$ configuration.

\subsection{Technoeconomic analysis}

Figure 15 compares the PVT collector designs proposed in this work to the reference PVT collector (CuS\&T_D8-n9), reporting percentage relative improvements relative to the latter. Positive improvements correspond to an increase in thermal efficiency $\left(\eta_{\mathrm{th}}\right)$, electrical efficiency $\left(\eta_{\mathrm{e}}\right)$ or heat removal factor $\left(F_{\mathrm{R}}\right)$, and to a reduction in the heat-loss coefficient $\left(U_{\mathrm{L}}\right)$ or payback time $(P B T)$. Of the different copper sheetand-tube designs, the largest thermal and electrical efficiency improvements (by $2.3 \%$ and 1.7\%, respectively) are obtained for the $n=18(D=8 \mathrm{~mm})$ case, although this design has a higher $P B T$ (by 2.6\%) than the reference case (with $n=9$ ), resulting in a negative $P B T$ improvement value in Figure 15. An intermediate case is the collector with 12 riser tubes $(D=8 \mathrm{~mm})$, with more modest thermal and electrical efficiency improvements $(1.1 \%$ and $0.8 \%$, respectively), but with almost no increase in the PBT. This suggests that the higher PVT collector price due to larger number of tubes is compensated, to a certain extent, by the increased cost savings achieved by this collector, thanks to the improved heat recovery.

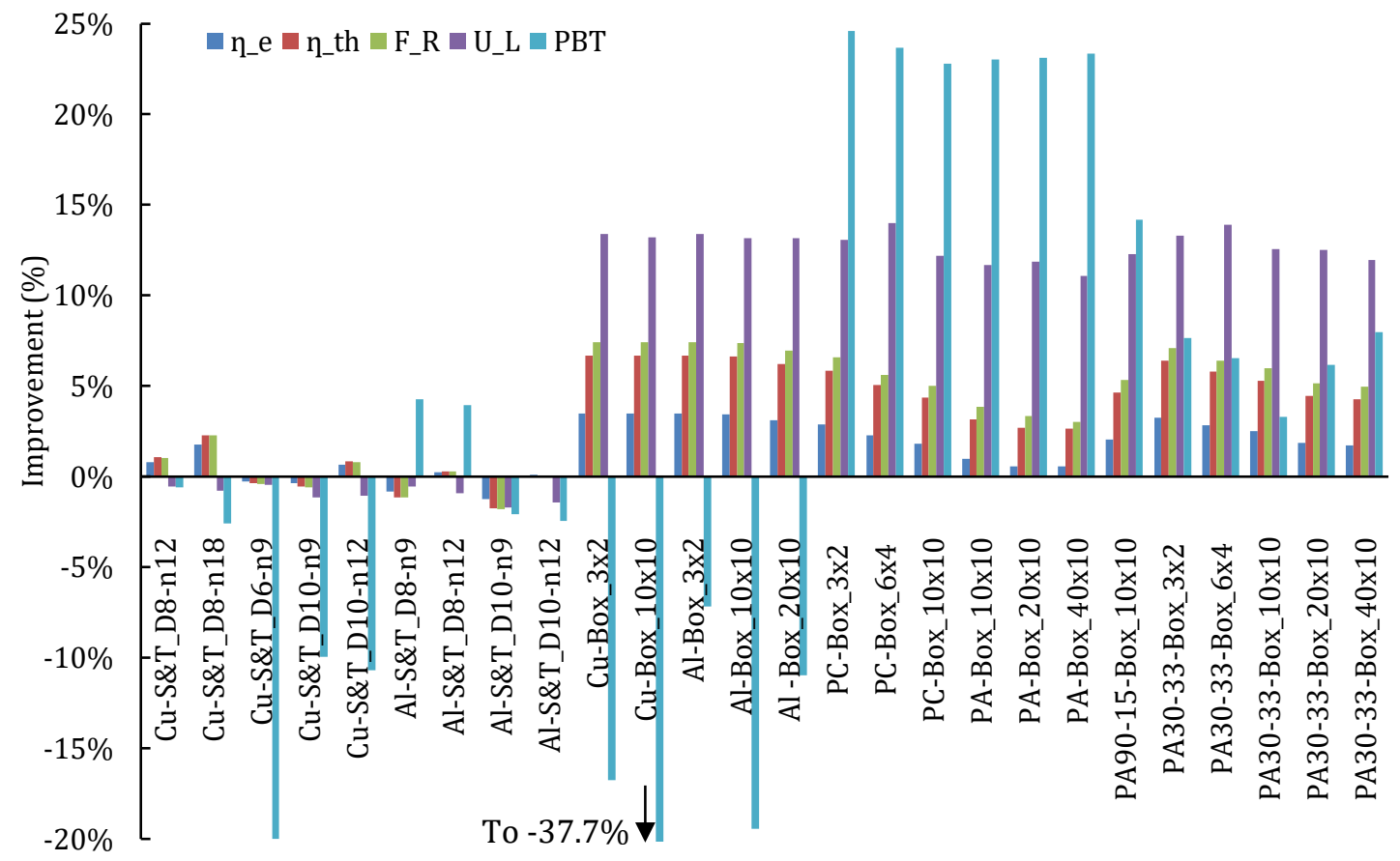

Figure 15. Percentage of improvement of the electrical $\left(\eta_{\mathrm{e}}\right)$ and thermal $\left(\eta_{\mathrm{t}}\right)$ efficiency, heat removal factor, $\left(F_{\mathrm{R}}\right)$, overall heat-loss coefficient $\left(U_{\mathrm{L}}\right)$ and payback time (PBT) of the different PVT designs studied compared to the reference PVT collector ( $\left.C u-S \& T_{-} D 8-n 9\right)$. 
Turning to the aluminium sheet-and-tube collectors, the reference design (Al-S\&T_D8-n9) has a slightly lower electrical (-0.8\%) and thermal (-1.1\%) performance than the equivalent copper reference collector, due to the marginally higher $(0.5 \%)$ overall heat-loss coefficient $\left(U_{\mathrm{L}}\right)$ and lower $(1.1 \%)$ heat removal factor $\left(F_{\mathrm{R}}\right)$, but its lower investment cost (-5\%) leads to a shorter PBT (4.3\% lower than the reference case). As with the copper collectors discussed above, the aluminium sheet-and-tube collector with 12 riser tubes ( $D=8 \mathrm{~mm}$ ) performs the best, also with $4 \%$ lower $P B T$ and $11.7 \%$ less weight than the reference collector, so it can be concluded that this design is a good alternative for decreasing the weight and cost of the PVT collector while maintaining the electrical efficiency and slightly increasing the thermal efficiency.

Figure 16 shows that all the flat-box designs outperform the reference PVT collector, with higher electrical (0.6-3.5\%) and thermal (2.7-6.7\%) efficiencies, as more heat can be extracted thanks to the higher heat transfer area of the channels. This also leads to higher (3.0-7.4\%) $F_{\mathrm{R}}$ and lower (11.1-14.0\%) $U_{\mathrm{L}}$. Among them, the PA absorber-exchanger designs perform the worst, as PA has the lowest thermal conductivity (see Table 2), while the copper and aluminium flat-box designs perform the best, as expected. In terms of channel dimensions, it is observed that the electrical and thermal efficiencies increase as the channel dimensions decrease, as more heat can be extracted, also leading to lower overall heat-loss coefficients (see Figure 16). When bringing costs into consideration, the results show that all flat-box designs have a lower PBT than the reference PVT collector (up to $24.6 \%$ lower), except for the copper and aluminium flat-box designs which have up to $37.7 \%$ higher $P B T$, due to the significantly higher PVT collector cost. This can be clearly observed in Figure 16, where the copper and aluminium flat-box designs (blue squares and dark blue crosses respectively) considerably differ from the rest of the data. The higher PVT collector costs of these designs compared to the other alternatives is attributed to two main factors: i) the increased amount of required construction material for the flat-box structure than for the sheet-and-tube configuration, and ii) the higher cost of copper and aluminium than that of polymer, which are not outweighed by the higher cost savings.

The results for the copper sheet-and-tube designs show that all such designs (unfilled circles) are worse than the reference case except the Cu-S\&T_D8-n12 $\left(C_{0}=386.0 €\right)$ and Cu-S\&T_D8-n18 $\left(C_{0}=398.0 €\right)$ collector designs, which corroborates the previous observations. From the aluminium sheet-and-tube collectors (purple pluses), the Al-S\&T_D8-n12 design $\left(C_{0}=366.0 €\right)$ appears as a promising alternative to the reference case, with lower PVT collector cost and slightly higher cost savings.

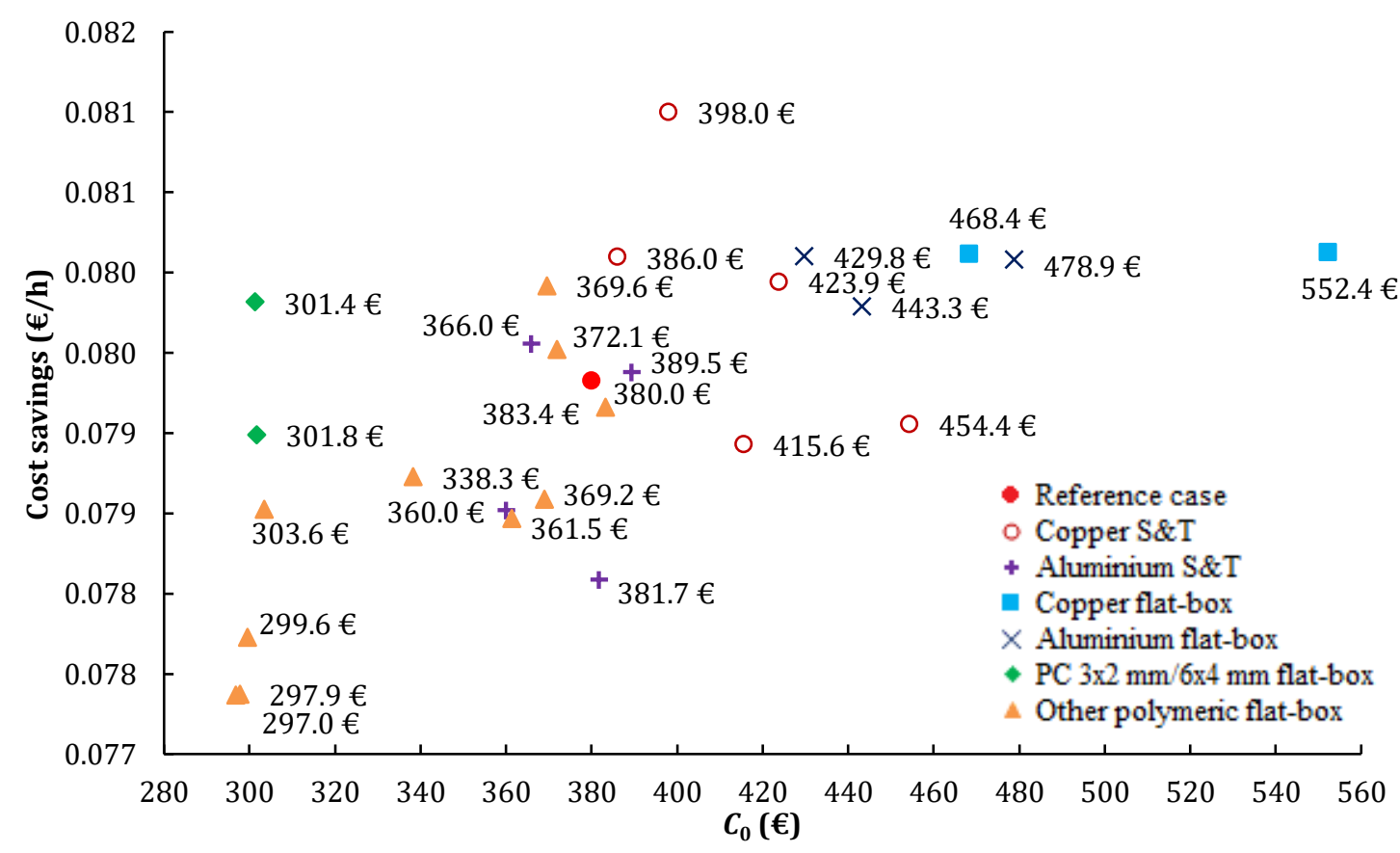

Figure 16. Cost savings $(€ / h)$ vs. PVT collector cost for the different designs studied. Results of the flat-box designs reproduced from previous work [65]. 
Considering the polymeric flat-box designs, the worst results are found for the PA with higher loading of additives (PA30-33) due to the high cost of the additive (orange triangles above and below the reference collector), but still the designs with smaller channels $(3 \times 2 \mathrm{~mm}$ and $6 \times 4 \mathrm{~mm})$ have higher cost savings than the reference collector. Conversely, the lowest collector costs are when using PC and PA without additives, as expected, due to the lower cost of the raw material (orange triangles appearing on the left of Figure 16). From these, the best results are obtained for the PC flat-box design, in particular the $3 \times 2 \mathrm{~mm}$ and $6 \times 4 \mathrm{~mm}$ (upper and lower green diamonds, respectively) with which high cost savings are achieved, compared to the rest of the channel designs. Thus, the PC-box- $3 \times 2$ and PC-box- $6 \times 4$ collector designs appear as the most promising alternatives, with $24.6 \%$ and $23.7 \%$ lower $P B T$, and $8.7 \%$ and $8.5 \%$ lower weight respectively, relative to the reference case collector.

\section{Further Discussion and Conclusions}

The potential of improved hybrid PVT collectors with an optimal balance of performance, weight, cost and ease of manufacture has been investigated, in an attempt to achieve an optimal use of the solar energy resource. An analysis of copper sheet-and-tube (Cu-S\&T) collectors showed that the pipe diameter does not have an important effect on the thermal efficiency of this collector design, whereas an increase in the number of riser tubes significantly improves its thermal and electrical efficiencies up to about 20-25 pipes, beyond which both efficiencies asymptote. However, when collectors with more riser pipes have higher payback periods due to their higher investment costs, which is not outweighed by their slightly better thermal performance (up to 2.3\%). Similar results were obtained for aluminium sheet-and-tube (Al-S\&T) collectors, although in this case the lower material cost allows lower investment costs that outweigh the slightly worse thermal performance of the absorber-exchanger caused by the lower thermal conductivity of aluminium. Therefore, an aluminium design is considered an interesting alternative to the reference copper case, as it maintains the electrical/thermal efficiencies while reducing both the investment cost (by 3.7\%) and the weight (by 11.7\%) of the collector.

All flat-box collectors outperformed the reference S\&T collector, due to the increased heat transfer area between the absorber and the fluid. Furthermore, the temperature distribution over the PV cells is more uniform in the flat-box designs, which alleviates hot spots and leads to lower cell temperatures, compared to those observed in the S\&T designs. As a consequence, although the thermal conductivity of the considered polymers is considerably lower than that of copper, all of the flat-box designs achieve a higher (up to 4.8\%) optical efficiency $\left(\eta_{0}\right)$ and a lower (up to $15.7 \%$ ) heat-loss coefficient $\left(a_{1}\right)$ compared to the reference collector.

Furthermore, the effect of the channel dimensions and the solid construction material on collector's performance were studied. Results indicate that the critical factor in achieving a good thermal and electrical performance (in the investigated collectors) is to maximise the heat transfer area rather than to minimise the thermal resistance, thereby extracting the maximum amount of heat from the absorber-exchanger. It should be noted that the proposed designs have a thin absorber plate $(1 \mathrm{~mm})$ and low fluid velocities (resulting in laminar flows). Thus, the effect of varying the materials and channel dimensions on the PVT collector performance, while observable, is small and not considered significant within the operational range proposed in this study.

A conservative structural preliminary analysis for selected PVT collector designs, showed that the proposed flatbox designs appear as a promising alternative to the reference S\&T collector with small vertical displacements due to weight of $<1 \%$ (of the collector length) and with lower maximum von Mises stresses. Therefore, these flatbox designs are not expected to suffer higher strains than commercially available PVT collectors, but they are expected to achieve higher thermal efficiencies at lower investment costs, thus lower payback periods.

Finally, an economic analysis revealed that the slightly better thermal and electrical performance of the copper and aluminium flat-box designs does not compensate their higher investment costs. It was also found that polymer loading with additives to increase thermal conductivity considerably increases the collector cost, while only achieving marginal cost savings (in line with the observations relating to the role of the thin absorber plate). Consequently, that flat-box designs from off-the-shelf polymers are a promising alternative to commercial collectors, without additives. These configurations can achieve an improvement in the thermal and electrical performance of the collector, while lowering the investment cost by up to $22 \%$ and weight up to $10 \%$. Specifically, the results showed that a PC $3 \times 2 \mathrm{~mm}$ flat-box design can achieve the lowest payback period $(24.6 \%$ lower than the reference $\mathrm{Cu}-\mathrm{S} \& \mathrm{~T}$ collector) due to the 
lower investment cost (21\% lower) and better thermal/electrical efficiencies (5.9\%/2.9\% higher), also leading to a $9 \%$ reduction in the total collector weight, which implies a promising reduction in the energy consumption and costs associated with collector manufacture, transport and installation.

Even though transport, installation and other costs have not been considered in the present research, these issues are of importance, together with the life cycle energy and environmental impact of the construction materials, recyclability, etc. Therefore, life cycle impact assessments are proposed as further work to fully characterise the proposed novel designs from performance, economic and environmental perspectives. In addition, further work is also required to: i) analyse in detail the structural and energy performance of the whole PVT collector in the 3-D CFD-FEM model, to consider also the effect of the sides of the PVT collector, ii) manufacture a prototype of the proposed PVT collector design and undertake experimental analysis to assess its real performance, iii) assess the energy performance of a complete PVT-based solar combined heat and power (S-CHP) system throughout the whole year when installed in a building.

\section{Acknowledgements}

This work was undertaken as part of the PhD Programme 'Renewable Energies and Energy Efficiency' of the University of Zaragoza - CIRCE Research Institute, during the international placement of María Herrando at Imperial College London that was partially funded by the University of Zaragoza, Fundación Bancaria Ibercaja and Fundación CAI under the CAI-Ibercaja Program of Research Placements [reference number IT9/16]. This work was also supported by the UK Engineering and Physical Sciences Research Council (EPSRC) [grant number EP/M025012/1]. The technical specifications and some experimental results relating to the commercially available ECOMESH panel were provided by the PVT collector manufacturer, EndeF Engineering. Part of this work was presented at the ISES EuroSun 2016 Conference. Data supporting this publication can be obtained on request from cep-lab@imperial.ac.uk. 


\section{Appendix A. 3-D CFD-FEM modelling details}

The detailed 3-D CFD-FEM model of the PVT collector involving a number of physics (heat transfer, fluid dynamics and solid mechanics) is described here. This model has been developed in the COMSOL platform taking advantage of its capability of solving complex 3-D multi-physics problems. The two main multiphysics involved are non-isothermal flow and thermal expansion. All equations are discretized using the finite elements method (FEM) and the solver used is a direct solver, specifically MUMPs.

\section{A.1 Heat transfer}

Heat transfer equations apply to all domains conforming the PVT collector (i.e., cover and inner glasses, inert gas gap, PV layer, EVA and Tedlar layers, absorber plate and riser pipes, circulating fluid and insulation).

\section{A1.1 Governing equations}

The total energy balance equation reads:

\section{Accumulation of Energy in System = Input of Energy into System - Output of Energy from System}

It can be expressed in a number of different ways. In this case, the expression of Eq. (A.1) is used, where the first term on the left corresponds to the accumulation of internal energy and the second one to the heat transfer by molecular transport due to temperature gradient (conduction). The term $Q$ on the right side of Eq. (A.1) is the heat source (or sink), which is zero in this case,

$$
\rho c_{\mathrm{P}} \boldsymbol{u} \cdot \boldsymbol{\nabla} T+\boldsymbol{\nabla} \cdot(-k \boldsymbol{\nabla} T)=Q .
$$

The problem is considered to be a quasi-steady-state process, so that the time derivative is zero.

\section{A1.2 Boundary conditions}

To solve this problem, a number of boundary conditions (BC) are needed. In particular, BCs on the external surfaces of the PVT collector, on the glasses and on the PV layer.

According to Ref. [93], the radiative heat transfer between two diffuse and infinity grey parallel plates of equal area at known temperatures, which is assumed here to be the case between the glass cover and the PV glass cover (with emissivity at long wavelengths, $\varepsilon_{\mathrm{PV}, \text { long }}$ ), can be obtained from,

$$
q_{\mathrm{rd}, \mathrm{g} 1 \mathrm{~g} 2}=\sigma_{\frac{T_{\mathrm{g} 2}^{4}-T_{\mathrm{g} 1}^{4}}{1 / \varepsilon_{\mathrm{PV}, \text { long } \lambda}{ }^{1} / \varepsilon_{\mathrm{g}, \text { long } \lambda}{ }^{-1}}}
$$

where $T_{\mathrm{g} 1}$ and $T_{\mathrm{g} 2}$ are the temperatures of the outer glass cover and the PV glass cover, respectively, and $\sigma$ is the Stefan-Boltzmann constant $\left(\sigma=5.67 \cdot 10^{-8} \mathrm{~W} / \mathrm{m}^{2} \mathrm{~K}^{4}\right)$.

The amount of solar irradiance $(S)$ perpendicular to the upper surface of the PVT collector, per unit area, which is absorbed by the PV is expressed in Eq. (A.3),

$$
S=(\tau \alpha)_{\mathrm{PV}} I_{\mathrm{t}}
$$

where $I_{\mathrm{t}}$ is the total incident solar irradiance, and $(\tau \alpha)_{\mathrm{PV}}$ is the transmittance-absorptance product for the PV module, which can be calculated as [93],

$$
(\tau \alpha)_{\mathrm{PV}}=\frac{\tau_{\mathrm{g}, \mathrm{short} \lambda} \alpha_{\mathrm{PV}, \text { short } \lambda}}{1-\left(1-\alpha_{\mathrm{PV}, \text { short } \lambda}\right) \rho_{\mathrm{d}}} .
$$

Here, $\tau_{\mathrm{g} g h o r t \lambda}$ is the transmittance of the cover plate (glass), $\alpha_{\mathrm{PV}, \text { short }}$ is the absorptivity of the PV module, both at short wavelengths, and $\rho_{\mathrm{d}}$ is the diffuse reflectance of the cover plate. In the case of a single cover glass layer, as used in the present study, we employ a value of 0.16 for this parameter [93].

The top losses from the outer glass cover are mainly due to convection to the ambient, radiation from the outer glass cover to the atmosphere and radiation from the PV layer to the atmosphere due to glass transmittance at long wavelengths [12,29,94]; first, second and third terms, respectively, in Eq. (A.5),

$$
q_{\text {top }}=q_{\text {cv,top }}+\varepsilon_{\text {g,long } \lambda} \sigma\left(T_{\mathrm{g} 1}^{4}-T_{\text {sky }}^{4}\right)+\tau_{\text {g,long } \lambda} \varepsilon_{\mathrm{PV}} \sigma\left(T_{\mathrm{PV}}^{4}-T_{\text {sky }}^{4}\right),
$$

where $\tau_{\mathrm{g}, \text { long }}$ is the transmittance of the cover glass and $\varepsilon_{\mathrm{PV}, \text { longג }}$ is the emissivity of the PV layer both at long 
wavelengths, $T_{\mathrm{PV}}$ is the temperature of the PV layer and $T_{\text {sky }}$ is the sky temperature which can be found from the relation $T_{\text {sky }}=0.0552 T_{\mathrm{a}}{ }^{1.5}[12,33,59,93]$, with $T_{\mathrm{a}}$ (ambient temperature) in $\mathrm{K}$.

In order to model the convective heat exchange with the surroundings, the effect of the wind should be considered, and so a forced convective heat transfer coefficient is required [71]. Various expressions are given in different sources for the estimation of this coefficient $[13,59,61,95,96]$, all of them dependent on the wind speed ( $\left.v_{\text {wind }}\right)$. These expressions do not differ significantly, and so it was decided to use the expression that provides intermediate values, within the range of the various predictions [12]. Hence:

$$
\begin{gathered}
q_{\mathrm{cv}, \text { top }}=h_{\mathrm{cv}, \text { wind }}\left(T_{\mathrm{g} 1}-T_{\mathrm{a}}\right), \\
h_{\mathrm{cv}, \text { wind }}=4.5+2.9 v_{\text {wind }} .
\end{gathered}
$$

Bottom losses are due to convection to the ambient and are expressed in Eq. (A.8),

$$
q_{\mathrm{cv}, \mathrm{back}}=U_{\mathrm{back}}\left(T_{\mathrm{abs}}-T_{\mathrm{a}}\right),
$$

where $U_{\text {back }}$ is the heat transfer coefficient between the absorber plate and the environment (through the back-layer insulation), which can be calculated from,

$$
U_{\text {back }}=\frac{1}{\frac{\delta_{\text {ins }}}{k_{\text {ins }}} \frac{1}{h_{\text {cv, b }}}},
$$

where $\delta_{\text {ins }}$ and $k_{\text {ins }}$ are the thickness and thermal conductivity of the insulation layer respectively, and $h_{\mathrm{cv}, \mathrm{b}}$ is the convective heat transfer coefficient of air at the back of the PVT collector, which usually takes values between $0.3-0.6 \mathrm{~W} / \mathrm{m}^{2} \mathrm{~K}$ [94]; so an average value of $0.45 \mathrm{~W} / \mathrm{m}^{2} \mathrm{~K}$ was considered in the present work [13].

Finally, PV energy conversion to electricity is estimated using Eq. (A.10); where $\eta_{\mathrm{PV}}$ corresponds to the PV conversion efficiency. $\eta_{\mathrm{PV}}$ varies with temperature and can be estimated as expressed in Eq. (A.11) $[12,26,64,71]$; where $\eta_{\text {ref }}$ corresponds to the PV efficiency at nominal operation conditions given by the manufacturer: solar irradiance of $1,000 \mathrm{~W} / \mathrm{m}^{2}$ and $T_{\text {ref, }}$ of $25^{\circ} \mathrm{C} ; \beta_{0}$ is the temperature coefficient for the PV module, also given in the technical specifications of the ECOMESH panel being considered.

$$
\begin{gathered}
w_{e}=I_{\mathrm{t}} \tau_{\mathrm{g}, \mathrm{short} \lambda} \eta_{\mathrm{PV}}, \\
\eta_{\mathrm{PV}}=\eta_{\mathrm{ref}}\left[1-\beta_{0}\left(T_{\mathrm{PV}}-T_{\mathrm{ref}}\right)\right] .
\end{gathered}
$$

\section{A.2 Fluid dynamics}

Fluid dynamic equations apply to both liquid (circulating water) and gas (inert gas in the gap) domains.

\section{A2.1 Governing equations (laminar flow)}

To apply the fluid-dynamic equations: mass and linear momentum conservation at steady-state (Eqs. (A.12) and (A.13), respectively), it is necessary to distinguish laminar from turbulent flow in natural or forced convection regimens. Dimensionless numbers, such as Reynolds $(R e)$ and Grashof ( $G r$ ) numbers, provide an indication of the type of flow of a system under certain conditions. For $R e>10^{6}$ and $\mathrm{Gr}>10^{9}$, it is assumed turbulent flow, and for $R e<10^{5}$ and $G r<5 \cdot 10^{8}$, laminar flow is assumed [97]. This dimensionless numbers can be calculated from the geometry of the problem, the pressure and the temperature conditions, and the gas properties. In the present problem laminar flow occurs in all case studies (with $R e<300$ ).

$$
\begin{gathered}
\rho(\boldsymbol{u} \cdot \boldsymbol{\nabla}) \boldsymbol{u}=\boldsymbol{\nabla} \cdot\left[-P\left|+\mu\left(\boldsymbol{\nabla} \boldsymbol{u}+(\boldsymbol{\nabla} \boldsymbol{u})^{\mathbf{T}}\right)-\frac{2}{3} \mu(\boldsymbol{\nabla} \cdot \boldsymbol{u})\right|\right]+\boldsymbol{F}_{\mathbf{V}}, \\
\boldsymbol{\nabla} \cdot(\rho \boldsymbol{u})=0
\end{gathered}
$$

where $P$ is the fluid pressure, $\mid$ is the unit tensor, $\boldsymbol{u}$ is the velocity vector, $\mu$ is the dynamic viscosity of the fluid and $\boldsymbol{F}_{\mathrm{V}}$ is the volume force due to gravity on the fluid domains, calculated as,

$$
\boldsymbol{F}_{\mathbf{V}}=-\rho g(\cos \theta \widehat{\boldsymbol{k}}+\sin \theta \hat{\boldsymbol{\jmath}}),
$$

where $\theta$ is the tilt angle of the PVT collector and $g$ the acceleration of gravity $\left(9.81 \mathrm{~m} / \mathrm{s}^{2}\right)$. 


\section{A2.2 Boundary conditions}

A number of BCs are again necessary to solve Eqs. (A.12) and (A.13). For all the fluid domains, i.e., Argon gas between the outer glass cover and the PV glass cover, and water flowing through the riser tubes, nonslip condition is imposed on the walls Eq. (A.15),

$$
\boldsymbol{u}=\mathbf{0}
$$

The Argon gas occupies an enclosed cavity, thus there is not exchange of gas with the surroundings. In the case of the water flowing through the riser tubes, water enters the pipes from one side of the PVT collector ( $y=0$ in Figure A.1) and leaves at the collector end, $(y=L$ in Figure A.1); thus, flowing longitudinally along the PVT collector. In this case, two more BCs are needed: the inlet mass flow rate $\left(\dot{m}_{\text {tube }}\right)$ at the inlet surface, known for each particular case, and non-compressive fluid condition (no overpressure $\left(P_{o}\right)$ at the outlet domain surface; $\left.P_{o}=0\right)$.

\section{A.3 Solid mechanics}

\section{A3.1 Governing equations}

Solid mechanic equations are evaluated for all solid domains.

The balance of linear momentum for an isotropic linear elastic solid at steady state reads,

$$
\mathbf{0}=\boldsymbol{\nabla} \cdot \boldsymbol{\sigma}_{c}+\boldsymbol{F}_{\mathbf{V}},
$$

where $F_{\mathrm{V}}$ is a volume force due to gravity and $\sigma_{c}$ is the Cauchy stress tensor defined as,

$$
\sigma_{c}=\lambda \mid \operatorname{tr}(\boldsymbol{\varepsilon})+G\left(\boldsymbol{\varepsilon}+\boldsymbol{\varepsilon}^{T}\right) .
$$

where $\varepsilon$ is the strain tensor containing also the thermoelastic strains due to the thermal expansion, $\lambda$ is the Lame constant and $G$ is the shear modulus.

Eq. (A.16) is applied to all solid domains to obtain the strains to which the different domains are subjected to due to temperature gradients and other external forces which may be applied on each domain.

\section{A3.2 Boundary conditions}

BCs necessary to solve the equation of motion are: free and prescribed displacements, fixed constrains, and volume forces. In this case, fixed constrain is imposed at the PVT collector water inlet, as it is assumed that the PVT collector is completely fixed with the frame at the collector water inlet. Meanwhile, prescribed displacement is imposed at the PVT collector water outlet, as the frame has some tolerance, allowing expansion in the flow direction ( $y$-direction) and along the collector width ( $x$-direction) but not allowing displacement in the $z$-direction (collector height) (see Figure A.1). Volume force, $F_{\mathrm{V}}$, is the gravity force, and it is calculated as expressed in Eq. (A.14), for all domains.

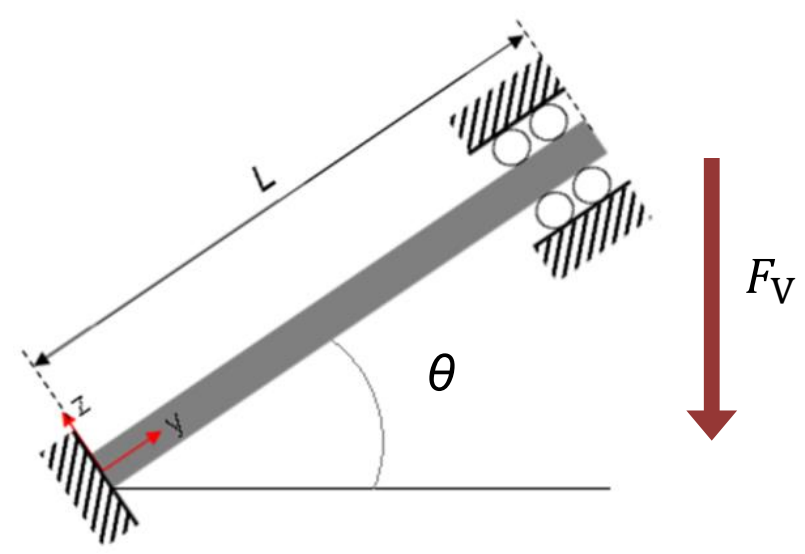

Figure A.1. Boundary conditions of the solid mechanics problem. 


\section{Appendix B. PVT collector design details}

Table B.1 presents the main characteristics of all the simulated models, including dimension and number of pipes/channels, overall thickness, overall flow cross area, pipes/channels transversal area, speed of water through the pipes/channels and Reynolds numbers.

Table B.1 Details of the absorber-exchanger designs studied. Here, $D$ refers to external diameter, $n$ to the number of riser pipes/channels. It should be noted that all designs have an aperture area of $0.948 \times 1.58 \mathrm{~m}$ (PVT collector width $\times$ length), and that the thickness of the absorber plate is $0.5 \mathrm{~mm}$ in the sheet-and-tube (S\&T) configuration and $1 \mathrm{~mm}$ in the flat-box configuration.

\begin{tabular}{|c|c|c|c|c|c|c|c|c|c|}
\hline & $\begin{array}{l}\text { PVT absorber- } \\
\text { exchanger design }\end{array}$ & $\begin{array}{l}\text { Dimensions } \\
(\mathbf{m m})\end{array}$ & $n$ & $\begin{array}{c}\text { PVT } \\
\text { thickness } \\
\text { (m) }\end{array}$ & $A_{\mathrm{p}}\left(\mathrm{m}^{2}\right)$ & $\begin{array}{c}A_{\mathrm{pT}}\left(A_{\mathrm{p}} \cdot n\right) \\
\left(\mathrm{m}^{2}\right)\end{array}$ & $\begin{array}{l}\dot{m}_{\text {tube }} \\
(\mathrm{kg} / \mathrm{s})\end{array}$ & $v_{w}(\mathrm{~m} / \mathrm{s})$ & $\boldsymbol{R} \boldsymbol{e}^{*}$ \\
\hline 1 & Cu-S\&T_D8-n9 & $D=8$ & 9 & $8.82 \cdot 10^{-2}$ & $3.32 \cdot 10^{-5}$ & $2.99 \cdot 10^{-4}$ & $9.26 \cdot 10^{-4}$ & $2.79 \cdot 10^{-2}$ & 181 \\
\hline 2 & Cu-S\&T_D8-n12 & $D=8$ & 12 & $8.82 \cdot 10^{-2}$ & $3.32 \cdot 10^{-5}$ & $3.98 \cdot 10^{-4}$ & $6.94 \cdot 10^{-4}$ & $2.09 \cdot 10^{-2}$ & 136 \\
\hline 3 & Cu-S\&T_D8-n18 & $D=8$ & 18 & $8.82 \cdot 10^{-2}$ & $3.32 \cdot 10^{-5}$ & $5.97 \cdot 10^{-4}$ & $4.63 \cdot 10^{-4}$ & $1.40 \cdot 10^{-2}$ & 91 \\
\hline 4 & Cu-S\&T_D6-n9 & $D=6$ & 9 & $8.62 \cdot 10^{-2}$ & $1.52 \cdot 10^{-5}$ & $1.37 \cdot 10^{-4}$ & $9.26 \cdot 10^{-4}$ & $6.09 \cdot 10^{-2}$ & 267 \\
\hline 5 & Cu-S\&T_D10-n9 & $D=10$ & 9 & $9.02 \cdot 10^{-2}$ & $5.54 \cdot 10^{-5}$ & $4.99 \cdot 10^{-4}$ & $9.26 \cdot 10^{-4}$ & $1.67 \cdot 10^{-2}$ & 140 \\
\hline 6 & Cu-S\&T_D10-n12 & $D=10$ & 12 & $9.02 \cdot 10^{-2}$ & $5.54 \cdot 10^{-5}$ & $6.65 \cdot 10^{-4}$ & $6.94 \cdot 10^{-4}$ & $1.25 \cdot 10^{-2}$ & 105 \\
\hline 7 & Al-S\&T_D8-n9 & $D=8$ & 9 & $8.82 \cdot 10^{-2}$ & $3.32 \cdot 10^{-5}$ & $2.99 \cdot 10^{-4}$ & $9.26 \cdot 10^{-4}$ & $2.79 \cdot 10^{-2}$ & 181 \\
\hline 8 & Al-S\&T_D8-n12 & $D=8$ & 12 & $8.82 \cdot 10^{-2}$ & $3.32 \cdot 10^{-5}$ & $3.98 \cdot 10^{-4}$ & $6.94 \cdot 10^{-4}$ & $2.09 \cdot 10^{-2}$ & 136 \\
\hline 9 & Al-S\&T_D10-n9 & $D=10$ & 9 & $9.02 \cdot 10^{-2}$ & $5.54 \cdot 10^{-5}$ & $4.99 \cdot 10^{-4}$ & $9.26 \cdot 10^{-4}$ & $1.67 \cdot 10^{-2}$ & 140 \\
\hline 10 & Al-S\&T_D10-n12 & $D=10$ & 12 & $9.02 \cdot 10^{-2}$ & $5.54 \cdot 10^{-5}$ & $6.65 \cdot 10^{-4}$ & $6.94 \cdot 10^{-4}$ & $1.25 \cdot 10^{-2}$ & 105 \\
\hline 11 & Cu-Box_3x2 & $3 \times 2$ & 236 & $8.27 \cdot 10^{-2}$ & $6.00 \cdot 10^{-6}$ & $1.42 \cdot 10^{-3}$ & $2.25 \cdot 10^{-5}$ & $3.74 \cdot 10^{-3}$ & 9 \\
\hline 12 & Cu-Box_10x10 & $10 \times 10$ & 86 & $9.07 \cdot 10^{-2}$ & $1.00 \cdot 10^{-4}$ & $8.60 \cdot 10^{-3}$ & $6.16 \cdot 10^{-5}$ & $6.16 \cdot 10^{-4}$ & 6 \\
\hline 13 & Al-Box_3x2 & $3 \times 2$ & 236 & $8.27 \cdot 10^{-2}$ & $6.00 \cdot 10^{-6}$ & $1.42 \cdot 10^{-3}$ & $2.25 \cdot 10^{-5}$ & $3.74 \cdot 10^{-3}$ & 9 \\
\hline 14 & Al-Box_10x10 & $10 \times 10$ & 86 & $9.07 \cdot 10^{-2}$ & $1.00 \cdot 10^{-4}$ & $8.60 \cdot 10^{-3}$ & $6.16 \cdot 10^{-5}$ & $6.16 \cdot 10^{-4}$ & 7 \\
\hline 15 & Al -Box_20x10 & $20 \times 10$ & 45 & $9.07 \cdot 10^{-2}$ & $2.00 \cdot 10^{-4}$ & $9.00 \cdot 10^{-3}$ & $1.18 \cdot 10^{-4}$ & $5.89 \cdot 10^{-4}$ & 8 \\
\hline 16 & PC-Box_3x2 & $3 \times 2$ & 236 & $8.27 \cdot 10^{-2}$ & $6.00 \cdot 10^{-6}$ & $1.42 \cdot 10^{-3}$ & $2.25 \cdot 10^{-5}$ & $3.74 \cdot 10^{-3}$ & 9 \\
\hline 17 & PC-Box_6x4 & $6 \times 4$ & 135 & $8.47 \cdot 10^{-2}$ & $2.40 \cdot 10^{-5}$ & $3.24 \cdot 10^{-3}$ & $3.93 \cdot 10^{-5}$ & $1.64 \cdot 10^{-3}$ & 8 \\
\hline 18 & PC-Box_10x10 & $10 \times 10$ & 86 & $9.07 \cdot 10^{-2}$ & $1.00 \cdot 10^{-4}$ & $8.60 \cdot 10^{-3}$ & $6.16 \cdot 10^{-5}$ & $6.16 \cdot 10^{-4}$ & 6 \\
\hline 19 & PA-Box_10x10 & $10 \times 10$ & 86 & $9.07 \cdot 10^{-2}$ & $1.00 \cdot 10^{-4}$ & $8.60 \cdot 10^{-3}$ & $6.16 \cdot 10^{-5}$ & $6.16 \cdot 10^{-4}$ & 6 \\
\hline 20 & PA-Box_20x10 & $20 \times 10$ & 45 & $9.07 \cdot 10^{-2}$ & $2.00 \cdot 10^{-4}$ & $9.00 \cdot 10^{-3}$ & $1.18 \cdot 10^{-4}$ & $5.89 \cdot 10^{-4}$ & 8 \\
\hline 21 & PA-Box_40x10 & $40 \times 10$ & 23 & $9.07 \cdot 10^{-2}$ & $4.00 \cdot 10^{-4}$ & $9.20 \cdot 10^{-3}$ & $2.30 \cdot 10^{-4}$ & $5.76 \cdot 10^{-4}$ & 9 \\
\hline 22 & PA90-15-Box_10x10 & $10 \times 10$ & 86 & $9.07 \cdot 10^{-2}$ & $1.00 \cdot 10^{-4}$ & $8.60 \cdot 10^{-3}$ & $6.16 \cdot 10^{-5}$ & $6.16 \cdot 10^{-4}$ & 6 \\
\hline 23 & PA30-33-Box_3x2 & $3 \times 2$ & 236 & $8.27 \cdot 10^{-2}$ & $6.00 \cdot 10^{-6}$ & $1.42 \cdot 10^{-3}$ & $2.25 \cdot 10^{-5}$ & $3.74 \cdot 10^{-3}$ & 9 \\
\hline 24 & PA30-33-Box_6x4 & $6 \times 4$ & 135 & $8.47 \cdot 10^{-2}$ & $2.40 \cdot 10^{-5}$ & $3.24 \cdot 10^{-3}$ & $3.93 \cdot 10^{-5}$ & $1.64 \cdot 10^{-3}$ & 8 \\
\hline 25 & PA30-33-Box_10x10 & $10 \times 10$ & 86 & $9.07 \cdot 10^{-2}$ & $1.00 \cdot 10^{-4}$ & $8.60 \cdot 10^{-3}$ & $6.16 \cdot 10^{-5}$ & $6.16 \cdot 10^{-4}$ & 6 \\
\hline 26 & PA30-33-Box_20x10 & $20 \times 10$ & 45 & $9.07 \cdot 10^{-2}$ & $2.00 \cdot 10^{-4}$ & $9.00 \cdot 10^{-3}$ & $1.18 \cdot 10^{-4}$ & $5.89 \cdot 10^{-4}$ & 8 \\
\hline 27 & PA30-33-Box_40x10 & $40 \times 10$ & 23 & $9.07 \cdot 10^{-2}$ & $4.00 \cdot 10^{-4}$ & $9.20 \cdot 10^{-3}$ & $2.30 \cdot 10^{-4}$ & $5.76 \cdot 10^{-4}$ & 9 \\
\hline
\end{tabular}

${ }^{*}$ Reynolds number (Re) is estimated at $20^{\circ} \mathrm{C}$ 


\section{References}

[1] Markides CN. The role of pumped and waste heat technologies in a high-efficiency sustainable energy future for the UK. Appl Therm Eng 2013;53:197-209. doi:10.1016/J.APPLTHERMALENG.2012.02.037.

[2] Markides CN. Low-Concentration Solar-Power Systems Based on Organic Rankine Cycles for Distributed-Scale Applications: Overview and Further Developments. Front Energy Reseach 2015;3:473389-47. doi:10.3389/fenrg.2015.00047.

[3] Freeman J, Hellgardt K, Markides CN. An assessment of solar-powered organic Rankine cycle systems for combined heating and power in UK domestic applications. Appl Energy 2015;138:605-20. doi:10.1016/J.APENERGY.2014.10.035.

[4] Freeman J, Hellgardt K, Markides CN. Working fluid selection and electrical performance optimisation of a domestic solar-ORC combined heat and power system for year-round operation in the UK. Appl Energy 2017;186:291-303. doi:10.1016/J.APENERGY.2016.04.041.

[5] Freeman J, Guarracino I, Kalogirou SA, Markides CN. A small-scale solar organic Rankine cycle combined heat and power system with integrated thermal energy storage. Appl Therm Eng 2017;127:1543-54. doi:10.1016/J.APPLTHERMALENG.2017.07.163.

[6] Ramos A, Chatzopoulou MA, Freeman J, Markides CN. Optimisation of a high-efficiency solar-driven organic Rankine cycle for applications in the built environment. Appl Energy 2018;228:755-65. doi:10.1016/J.APENERGY.2018.06.059.

[7] Michael JJ, Iniyan S, Goic R. Flat plate solar photovoltaic-thermal (PV/T) systems: A reference guide. Renew Sustain Energy Rev 2015;51:62-88. doi:10.1016/j.rser.2015.06.022.

[8] Zondag HA. Flat-plate PV-Thermal collectors and systems: A review. Renew Sustain Energy Rev 2008;12:891-959. doi:10.1016/j.rser.2005.12.012.

[9] Allan J, Dehouche Z, Stankovic S, Mauricette L. Performance testing of thermal and photovoltaic thermal solar collectors. Energy Sci Eng 2015;3:310-26. doi:10.1002/ese3.75.

[10] Santbergen R, van Zolingen RJC. The absorption factor of crystalline silicon PV cells: A numerical and experimental study. Sol Energy Mater Sol Cells 2008;92:432-44. doi:10.1016/j.solmat.2007.10.005.

[11] Dupeyrat P, Ménézo C, Fortuin S. Study of the thermal and electrical performances of PVT solar hot water system. Energy Build 2014;68:751-5. doi:10.1016/j.enbuild.2012.09.032.

[12] Herrando M, Markides CN, Hellgardt K. A UK-based assessment of hybrid PV and solar-thermal systems for domestic heating and power: System performance. Appl Energy 2014;122:288-309. doi:10.1016/j.apenergy.2014.01.061.

[13] Antonanzas J, del Amo A, Martinez-Gracia A, Bayod-Rujula AA, Antonanzas-Torres F. Towards the optimization of convective losses in photovoltaic-thermal panels. Sol Energy 2015;116:323-36. doi:10.1016/j.solener.2015.04.013.

[14] Makki A, Omer S, Sabir H. Advancements in hybrid photovoltaic systems for enhanced solar cells performance. Renew Sustain Energy Rev 2015;41:658-84. doi:10.1016/j.rser.2014.08.069.

[15] Daghigh R, Ruslan MH, Sopian K. Advances in liquid based photovoltaic/thermal (PV/T) collectors. Renew Sustain Energy Rev 2011;15:4156-70. doi:10.1016/j.rser.2011.07.028.

[16] Chow TT. A review on photovoltaic/thermal hybrid solar technology. Appl Energy 2010;87:365-79. doi:10.1016/j.apenergy.2009.06.037.

[17] Zhang X, Zhao X, Smith S, Xu J, Yu X. Review of R\&D progress and practical application of the solar photovoltaic/thermal (PV/T) technologies. Renew Sustain Energy Rev 2012;16:599-617. doi:10.1016/j.rser.2011.08.026.

[18] Herrando M, Ramos A, Freeman J, Zabalza I, Markides CN. Technoeconomic modelling and optimisation of solar combined heat and power systems based on flat-box PVT collectors for domestic applications. Energy Convers Manag 2018;175:67-85. doi:10.1016/j.enconman.2018.07.045.

[19] Fudholi A, Sopian K, Yazdi MH, Ruslan MH, Ibrahim A, Kazem HA. Performance analysis of photovoltaic thermal (PVT) water collectors. Energy Convers Manag 2014;78:641-51. doi:10.1016/j.enconman.2013.11.017.

[20] Hansen J, Sorensen H, Byström J, Collins M, Karlsson B. Market, Modelling, Testing and Demonstration in the Framework of IEA SHC Task 35 on PV/Thermal Solar Systems. IEA 2007;83:199-210.

[21] Affolter P, Eisenmann W, Fechner H, Rommel M, Schaap A, Sorensen H, Tripanagnostopoulos Y, Zondag H. PVT roadmap: A European guide for the development and market introduction of PV-Thermal technology. Present 20th Eur Photovolt Sol Energy Conf Exhib 2005;6:10.

[22] Guarracino I, Mellor A, Ekins-Daukes NJ, Markides CN. Dynamic coupled thermal-and-electrical modelling of sheet-and-tube hybrid photovoltaic / thermal (PVT) collectors. Appl Therm Eng 2016;101:778-95. doi:10.1016/j.applthermaleng.2016.02.056. 
[23] Kempener R, Burch J, Navntoft C, Mugnier D, Nielsen JE, Weiss W. Solar Heating and Cooling for Residential Applications. IEA-ETSAP and IRENA 2015.

[24] Guarracino I, Freeman J, Ekins-Daukes N, Markides CN. Performance assessment and comparison of solar ORC and hybrid PVT systems for the combined distributed generation of domestic heat and power. International Conference on Heat Transfer, Fluid Mechanics and Thermodynamics, 2016.

[25] Chow TT, Ji J, He W. Photovoltaic-Thermal Collector System for Domestic Application. J Sol Energy Eng 2007;129:205. doi:10.1115/1.2711474.

[26] Zondag HA, de Vries DW, van Helden WGJ, van Zolingen RJC, van Steenhoven AA. The yield of different combined PV-thermal collector designs. Sol Energy 2003;74:253-69. doi:10.1016/S0038092X(03)00121-X.

[27] Chow TT. Performance analysis of photovoltaic-thermal collector by explicit dynamic model. Sol Energy 2003;75:143-52. doi:10.1016/j.solener.2003.07.001.

[28] Kalogirou SA. Use of TRNSYS for modelling and simulation of a hybrid PV-thermal solar system for Cyprus. Renew Energy 2001;23:247-60. doi:10.1016/S0960-1481(00)00176-2.

[29] del Amo A, Martínez-Gracia A, Bayod-Rújula AA, Antoñanzas J. An innovative urban energy system constituted by a photovoltaic/thermal hybrid solar installation: Design, simulation and monitoring. Appl Energy 2016. doi:10.1016/j.apenergy.2016.07.011.

[30] EndeF Engineering. Technical Datasheet ECOMESH panel 2017. <www.ecomesh.es/?lang=en> (accessed 28/09/2018)

[31] Ji J, Han J, Chow TT, Yi H, Lu J, He W, Sun W. Effect of fluid flow and packing factor on energy performance of a wall-mounted hybrid photovoltaic/water-heating collector system. Energy Build 2006;38:1380-7. doi:10.1016/j.enbuild.2006.02.010.

[32] Chow TT, Chan ALS, Fong KF, Lin Z, He W, Ji J. Annual performance of building-integrated photovoltaic/water-heating system for warm climate application. Appl Energy 2009;86:689-96. doi:10.1016/j.apenergy.2008.09.014.

[33] Cristofari C, Notton G, Canaletti JL. Thermal behavior of a copolymer PV/Th solar system in low flow rate conditions. Sol Energy 2009;83:1123-38. doi:10.1016/j.solener.2009.01.008.

[34] Cristofari C, Notton G, Poggi P, Louche A. Modelling and performance of a copolymer solar water heating collector. Sol Energy 2002;72:99-112. doi:10.1016/S0038-092X(01)00092-5.

[35] Cristofari C, Canaletti J, Notton G, Darras C. Innovative patented PV/TH Solar Collector: optimization and performance evaluation. Energy Procedia 2012;14:235-40.

[36] Huang BJ, Lin TH, Hung WC, Sun FS. Performance evaluation of solar photovoltaic / thermal systems. Sol Energy 2001;70:443-8.

[37] Ghaffari Mosanenzadeh S, Liu MW, Osia A, Naguib HE. Thermal Composites of Biobased Polyamide with Boron Nitride Micro Networks. J Polym Environ 2015;23:566-79. doi:10.1007/s10924-015-0733-8.

[38] Herrando M, Markides CN. Hybrid PV and solar-thermal systems for domestic heat and power provision in the UK: Techno-economic considerations. Appl Energy 2016;161:512-32. doi:10.1016/j.apenergy.2015.09.025.

[39] International Energy Agency (IEA). Technology Roadmap: Solar Heating and Cooling. Paris (France), 2012.

[40] International Energy Agency (IEA). Task 60: PVT Systems: Application of PVT Collectors and New Solutions in HVAC Systems, 2018.

[41] Cuddihy EF, Coulbert CD, Willis P, Baum B, Garcia A, Minning C. Polymeric Encapsulation Materials for Low-Cost, Terrestrial, Photovoltaic Modules. Polym. Sol. Energy Util., vol. 220, AMERICAN CHEMICAL SOCIETY; 1983, p. 22-353. doi:doi:10.1021/bk-1983-0220.ch022.

[42] Rosenthal AL, Thomas MG, Durand SJ. A ten year review of performance of photovoltaic systems. 23rd IEEE Photovoltaic Specialists Conference, 1993:1289-91. doi:10.1109/PVSC.1993.346934.

[43] Czanderna AW, Pern FJ. Encapsulation of PV modules using ethylene vinyl acetate copolymer as a pottant: A critical review. Sol Energy Mater Sol Cells 1996;43:101-81. doi:10.1016/09270248(95)00150-6.

[44] Magalhães PMLP, Martins JFA, Joyce ALM. Comparative Analysis of Overheating Prevention and Stagnation Handling Measures for Photovoltaic-thermal (PV-T) Systems. Energy Procedia 2016;91:346-55. doi:10.1016/j.egypro.2016.06.282.

[45] Zondag HA, van Helden WGJ. Stagnation Temperature in PVT Collectors, 2002.

[46] Fortuin S, Hermann M, Stryi-Hipp G, Nitz P, Platzer W. Hybrid PV-thermal Collector Development: Concepts, Experiences, Results and Research Needs. Energy Procedia 2014;48:37-47. doi:10.1016/j.egypro.2014.02.006.

[47] Magalhães PMLP, Martins JFA, Joyce ALM. Performance Assessment of Tank Fluid Purging and Night Cooling as Overheating Prevention Techniques for Photovoltaic-Thermal (PV-T) Solar Water Heating 
Systems. IFIP International Federation for Information Processing, 2017:499:337-347. doi:10.1007/978-3-319-56077-9.

[48] Fischer J, Bradler PR, Schlaeger M, Wallner GM, Lang RW. Novel Solar Thermal Collector Systems in Polymer Design - Part 5: Fatigue Characterization of Engineering PA Grades for Pressurized Integrated Storage Collectors. Energy Procedia 2016;91:392-402. doi:10.1016/j.egypro.2016.06.167.

[49] Ramschak T, Hausner R, Fink C. Polymeric Materials in Solar-thermal Systems - Performance Requirements and Loads. Energy Procedia 2016;91:105-12. doi:10.1016/j.egypro.2016.06.182.

[50] Martinopoulos G, Missirlis D, Tsilingiridis G, Yakinthos K, Kyriakis N. CFD modeling of a polymer solar collector. Renew Energy 2010;35:1499-508. doi:10.1016/j.renene.2010.01.004.

[51] Tagliafico LA, Scarpa F, De Rosa M. Dynamic thermal models and CFD analysis for flat-plate thermal solar collectors - A review. Renew Sustain Energy Rev 2014;30:526-37. doi:10.1016/j.rser.2013.10.023.

[52] Selmi M, Al-Khawaja MJ, Marafia A. Validation of CFD simulation for flat plate solar energy collector. Renew Energy 2008;33:383-7. doi:10.1016/j.renene.2007.02.003.

[53] Marroquín-De Jesús Á, Olivares-Ramírez JM, Jiménez-Sandoval 0, Zamora-Antuñano MA, EncinasOropesa A. Analysis of Flow and Heat Transfer in a Flat Solar Collector with Rectangular and Cylindrical Geometry Using CFD. Ingeniería, Investigación y Tecnología, 2013;14:553-61. doi:10.1016/S14057743(13)72265-0.

[54] Henderson D, Junaidi H, Muneer T, Grassie T, Currie J. Experimental and CFD investigation of an ICSSWH at various inclinations. Renew Sustain Energy Rev 2007;11:1087-116. doi:10.1016/j.rser.2005.11.003.

[55] Singh Yadav A, Bhagoria JL. Heat transfer and fluid flow analysis of solar air heater: A review of CFD approach. Renew Sustain Energy Rev 2013;23:60-79. doi:10.1016/j.rser.2013.02.035.

[56] Corbin CD, Zhai ZJ. Experimental and numerical investigation on thermal and electrical performance of a building integrated photovoltaic-thermal collector system. Energy Build 2010;42:76-82. doi:10.1016/j.enbuild.2009.07.013.

[57] Moreno D, Fernandez M, Esquivias PM. A comparison of closed-form and finite-element solutions for heat transfer in a nearly horizontal, unglazed flat plate PVT water collector: Performance assessment. Sol Energy 2017;141:11-24. doi:10.1016/j.solener.2016.11.015.

[58] European committee for Standardisation. European Standard EN 12975-2, in, CEN, 2006.

[59] Notton G, Cristofari C, Mattei M, Poggi P. Modelling of a double-glass photovoltaic module using finite differences. Appl Therm Eng 2005;25:2854-77. doi:10.1016/j.applthermaleng.2005.02.008.

[60] Agarwal RK, Garg HP. Study of a Photovoltaic-Thermal system - Thermosyphonic solar water heater combined with solar cells. Energy Convers Manag 1994;35:605-20.

[61] Bhattarai S, Oh J, Euh S, Krishna G, Hyun D. Simulation and model validation of sheet and tube type photovoltaic thermal solar system and conventional solar collecting system in transient states. Sol Energy Mater Sol Cells 2012;103:184-93. doi:10.1016/j.solmat.2012.04.017.

[62] Sandnes B, Rekstad J. A photovoltaic/thermal (PV/T) collector with a polymer absorber plate. Experimental study and analytical model. Sol Energy 2002;72:63-73. doi:10.1016/S0038092X(01)00091-3.

[63] Zondag HA, De Vries DW, Van Helden WGJ, Van Zolingen RJC, van Steenhoven AA. The thermal and electrical yield of a PV-thermal collector. Sol Energy 2002;72:113-28. doi:10.1016/S0038092X(01)00094-9.

[64] Tiwari A, Sodha MS. Performance evaluation of solar PV/T system: An experimental validation. Sol Energy 2006;80:751-9. doi:10.1016/j.solener.2005.07.006.

[65] Herrando M, Guarracino I, del Amo A, Zabalza I, Markides CN. Energy Characterization and Optimization of New Heat Recovery Configurations in Hybrid PVT Systems. ISES Conference Proceedings, Eurosun 2016, Palma de Mallorca (Spain). doi:10.18086/eurosun.2016.08.22.

[66] ASHRAE Standard. Standard 93-2003: Methods of testing to determine the performance of solar collectors, 2013.

[67] ISO. ISO 9806:2013 (e) Solar energy - solar thermal collectors - test methods, 2013.

[68] Collins M, Zondag HA. Recommended standard for the characterization and monitoring of PV/Thermal systems. vol. Report DB2, 2009.

[69] Vokas G, Christandonis N, Skittides F. Hybrid photovoltaic - thermal systems for domestic heating and cooling - A theoretical approach. Sol Energy 2006;80:607-15. doi:10.1016/j.solener.2005.03.011.

[70] Anderson TN, Duke M, Morrison GL, Carson JK. Performance of a building integrated Photovoltaic/Thermal (BIPVT) solar collector. Sol Energy 2009;83:445-55. doi:10.1016/j.solener.2008.08.013. 
[71] Skoplaki E, Palyvos JA. On the temperature dependence of photovoltaic module electrical performance: A review of efficiency/power correlations. Sol Energy 2009;83:614-24. doi:10.1016/j.solener.2008.10.008.

[72] Chow TT, He W, Ji J. Hybrid photovoltaic-thermosyphon water heating system for residential application. Sol Energy 2006;80:298-306. doi:10.1016/j.solener.2005.02.003.

[73] He W, Chow T, Ji J, Lu J, Pei G. Hybrid photovoltaic and thermal solar-collector designed for natural circulation of water. Appl Energy 2006;83:199-210. doi:10.1016/j.apenergy.2005.02.007.

[74] MakeItFrom.com. Toughened (Tempered) Soda-Lime Glass. <www.makeitfrom.com/materialproperties/Toughened-Tempered-Soda-Lime-Glass> (accessed 7/02/2017).

[75] EndeF Engineering. EVASAFE DataSheet, 2017.

[76] GoodFellow. Tedlar - Polyvinylfluoride (PVF). <www.findtheneedle.co.uk/companies/ goodfellowcambridge-ltd/products/tedlar-polyvinylfluoride-pvf> (accessed 6/12/2016).

[77] Cambridge University Engineering Department. Materials data book. Mater Courses 2003:1-41. doi:10.1016/0261-3069(88)90026-X.

[78] Alanod Solar. Copper absorber plate, 2017.

[79] GoodFellow. Polycarbonate - online catalogue source - supplier of research materials in small quantities - Goodfellow. <www.goodfellow.com/E/Polycarbonate.html> (accessed 6/12/2016).

[80] Roylance D. Mechanical Properties of Materials. Springer 2008;190:645. doi:10.1007/978-94-007$4342-7$.

[81] Von Mises R. Mechanik der Festen Korper im Plastisch Deformablen Zustand. Math Phys 1913;1:58292.

[82] Hjelmstad KD. Fundamentals of Structural Mechanics. Second Edi. Urbana-Champaign, Illinois: Springer US; 2005.

[83] Herrando M, Ramos A, Zabalza I. Cost competitiveness of a novel PVT-based solar combined heating and power system: Influence of economic parameters and financial incentives. Energy Convers Manag 2018;166:758-70. doi:10.1016/j.enconman.2018.04.005.

[84] Preciogas. Natural gas price in Spain. <www.preciogas.com/conceptos/precio-kwh> (accessed $2 / 11 / 2016)$.

[85] Tarifaluzhora. Electricity price in Spain. <www.tarifaluzhora.es/precio-electricidad-espana> (accessed 2/11/2016).

[86] AITIIP. Technological Center <www.aitiip.com> (accessed 1/12/2016).

[87] EndeF. Endef - Energy, Development and Future, 2017.

[88] Alcaglas. Aluminum profile cut-to-size. <www.alcaglas.com/infer.php?gr=perfiles-amedida\&sg=chapas-perfiles-aluminio $>$ (accessed 2/08/2016).

[89] Guarracino I, Freeman J, Markides CN. Experimental validation of a 3-D dynamic solar- thermal collector model under time-varying environmental conditions. 29th International Conference on Efficiency, Cost, Optimization, Simulation and Environmental Impact of Energy Systems, 2016.

[90] Ibrahim A, Othman MY, Ruslan MH, Alghoul MA, Yahya M, Zaharim A, Sopian K. Performance of photovoltaic thermal collector (PVT) with different absorbers design. WSEAS Trans Environ Dev 2009;5:321-30.

[91] Ji J, Han J, Chow TT, Han C, Lu J, He W. Effect of flow channel dimensions on the performance of a boxframe photovoltaic/thermal collector. Proc Inst Mech Eng Part A-Journal Power Energy 2006;220:681-8. doi:10.1234/09576509jpe316.

[92] Bergene T, Lovvik OM. Model calculations on a flat-plate solar heat collector with integrated solar cells. Sol Energy 1995;55:453-62. doi:10.1016/0140-6701(96)88784-4.

[93] Duffie JA, Beckman WA, Worek WM. Solar Engineering of Thermal Processes. John Wiley \& Sons, 1974. doi:10.1115/1.2930068.

[94] Kalogirou SA. Solar energy engineering: processes and systems. $2^{\text {nd }}$ Edition, Academic Press, 2014. doi:10.1016/B978-0-12-374501-9.00014-5.

[95] Rejeb O, Dhaou H, Jemni A. Parameters effect analysis of a photovoltaic thermal collector: Case study for climatic conditions of Monastir, Tunisia. Energy Convers Manag 2015;89:409-19. doi:10.1016/j.enconman.2014.10.018.

[96] Lunde PJ. Solar thermal engineering: Space heating and hot water systems. John Wiley and Sons, 1980.

[97] Incropera FP, DeWitt DP, Bergman TL, Lavine AS. Fundamentals of Heat and Mass Transfer. $6^{\text {th }}$ Edition, John Wiley \& Sons, 2007. doi:10.1016/j.applthermaleng.2011.03.022. 